\title{
EL ORATORIO Y LOS FRESCOS DE LA ANUNCIACIÓN DE CORI: UN ANTIGUO CASO DE PATROCINIO CASTELLANO EN EL AGRO ROMANO
}

\author{
POR \\ PIO FRANCESCO PISTILLI - STEFANO PETROCCHI \\ Università di Roma «La Sapienza» \\ Sopraintendenza per i Beni storico-artistici del Lazio
}

\begin{abstract}
En las afueras de la puerta Romana de Cori, se alza el oratorio de la Anunciación, del S.XV, famoso por las pinturas que recubren sus paredes. La capilla fue construida por iniciativa del Municipio de Cori a principios de la segunda década del S.XV. Dicha institución fue patrocinada por Pedro Fernández de Frías, cardenal castellano que encargó un primer grupo de pinturas, realizadas por un artista de cultura úmbrico-romana. Entre 1426 y mediados del S.XV, otros patrocinadores, entre los que se hallaban los cardenales Carrillo de Albornoz y Juan Cervantes, contribuyeron a ultimar la decoración del oratorio en otros tres momentos diferentes.
\end{abstract}

Palabras clave: Pintura, s. xv. Roma. Pio Francesco Pistilli. Stefano Petrocchi. Pedro Fernández de Frías.

The fifteenth-century Oratory of the Annunciation, famous for the paintings covering its walls, is located outside of the Roman gate of Cori. The construction of this chapel was sponsored by the municipality of Cori around 1412, and patronized by the Spaniard Pedro Fernández de Frías. This Castillian cardinal commissioned the first group of paintings, carried out by an artist who was culturally related to Umbria and Rome. Between 1426 and the middle of the century, other patrons, among them cardinals Carrillo de Albornoz and Juan Cervantes, contributed to the termination of the decoration in three separate moments.

Words key: Painting, 15th century. Rome. Pio Francesco Pistilli. Stefano Petrocchi. Pedro Fernández de Frías.

\section{El monumento}

El oratorio de La Anunciación se halla situado en el área que circunda a Cori, en las inmediaciones de la puerta Romana, zona que actualmente se conoce con el topónimo de «Insito». El monumento se alza junto a la vía que unía desde época medieval el apartado centro de los montes Lepini con la ciudad de Cisterna y con la vía Pedemontana, una arteria que había sustituido a la vía Apia desde el s. viII en la ruta que atravesaba la región pontina ${ }^{1}$. La capilla

I Sobre la red viaria que comunicaba Cori con la via Pedemontana durante la Edad Media, cfr. J. Coste, «La via Appia nel Medio Evo e l'incastellamento», La via Appia. Decimo incontro di studio del Comitato per l'archeologia laziale, Roma 1990 (Quaderni del Centro di studio per l'archeologia Etrusco-Italica, 18), p. 134.

$A E A$, LXXVII, 2004, 305, pp. 35 a 57 


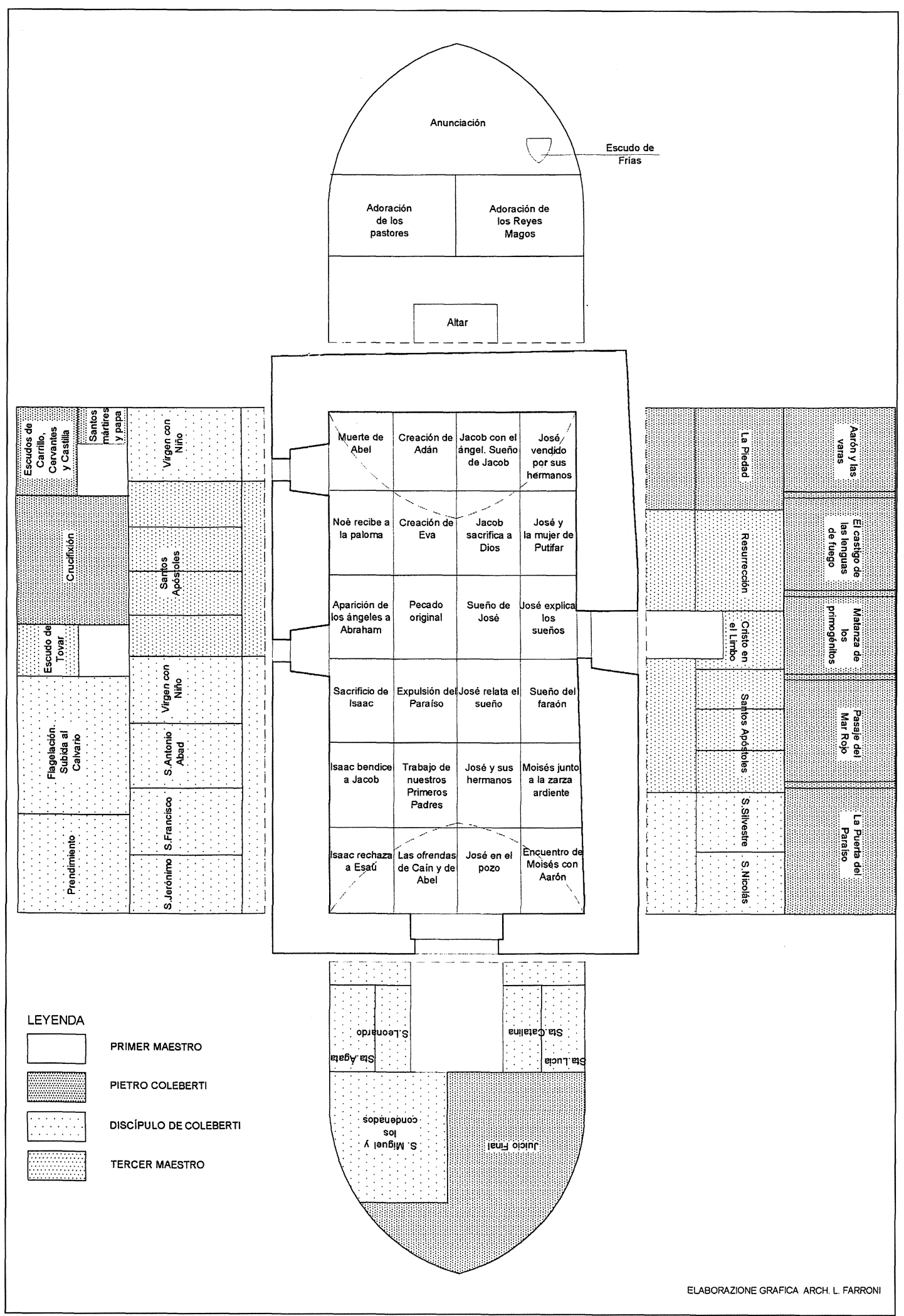

Fig. 1. Cori, Oratorio de La Anunciación, plano de las paredes y de la bóveda con los temas representados. AEA, LXXVII, 2004, 305, pp. 35 a 57 
conserva un ciclo de pinturas al fresco de gran interés que testimonia la época de la transición del arte gótico al primer renacimiento en el territorio que rodea a Roma. La atención que la crítica ha dedicado a las distintas manos de los pintores que se han sucedido en tal empresa decorativa ${ }^{2}$ ha olvidado, sin embargo, el conocimiento de la historia del monumento y de su patrocinio, aun cuando este condicione de forma directa la datación de la obra del primer maestro activo en el oratorio, que hasta ahora ha sido fijada a finales del s. XIv. Esta cronología se basaba fundamentalmente en la hipótesis que Federico Hermanin había formulado a principios del s. XIX a propósito del origen del oratorio de La Anunciación. Dicho estudioso había reconocido correctamente el escudo cardenalicio pintado al lado del episodio de La Anunciación (Fig. 3) en cuanto representativo del patrocinador más antiguo del oratorio si bien, y apoyándose en ese DE SPAGNIA FUIT con el que comienza la inscipción conmemorativa y anónima situada en la arquivolta de la portada de la fachada (Fig. 2), lo había referido a un Petrus Hispanus, un personaje de la Curia creado por la ferviente fantasía de Ciacconio que le había atribuido una nominación a la púrpura cardenalicia en 1378, así como también, desafortunadamente, un emblema muy parecido al que se halla representado en el fresco de Cori ${ }^{3}$.

El caso es que desde Hermanin casi nunca se ha puesto en tela de juicio esa datación a finales del s. XIV para el trabajo del primer autor de los frescos y ello porque se consideraba que su estilo (que en realidad no es legible siempre a causa de la decoración pictórica posterior) se encuadraba perfectamente en el panorama artístico regional de aquellos años ${ }^{4}$. Esta apreciación no tenía en cuenta, sin embargo, el conjunto arquitectónico que recibía aquella decoración ya que el tipo de aparejo murario, junto al correspondiente aspecto edilicio, atestiguan una cronología ligeramente más moderna y, por tanto, incompatible con cuanto se ha afirmado respecto de los frescos más antiguos.

La sospecha (que más tarde se revelaría fundada) de que todo esto derivase de una errónea individuación del primer patrocinador de La Anunciación, nos ha inducido a profundizar en la investigación sobre el emblema del cardenal anónimo circunscribiéndola a la serie de altos prelados castellanos que se hallaban presentes en Roma y en el Lacio meridional entre el 1410 y el 1430, es decir en el período en el que se puede colocar adecuadamente dicho monumento. La identificación con toda seguridad del emblema de La Anunciación con el del cardenal Pedro Fernández de Frías ha dilucidado, finalmente, la cuestión del personaje de la Curia que patrocinó la construcción del oratorio. En esta empresa dicho cardenal recibió ayuda del Municipio de Cori, cuyo emblema lapídeo se halla representado en la fachada, debajo de una moldura romana reutilizada que presenta entre los dentículos la lagunosa e indescifrable inscripción OREM DOMUS TUA, sobre la que el historiador local Sante Laurienti, de principios del s. XVII, diría «Ex quibus extrahi non potest sententia, cum non sit fortassis integer lapis» ${ }^{5}$. $\mathrm{Al}$ reconocimiento de las insignias de Pedro Fernández de Frías en las cinco torres de oro en

\footnotetext{
${ }^{2}$ F. Hermanin, «Le pitture della cappella dell'Annunziata a Cori presso Roma», L'Arte IX (1906), pp. 45-52; R. van Marle, The Development of the Italian Schools of Painting VIII, La Haya 1927, pp. 394-399; H.L. Kessler, «L'antica basilica di San Pietro come fonte e ispirazione per la decorazione delle chiese medievali», Fragmenta picta. Affreschi e mosaici staccati del Medioevo romano, Roma 1989, pp. 60 y 62; S. Romano, Eclissi di Roma. Pittura murale a Roma e nel Lazio da Bonifacio VII a Martino V (1295-1431), Roma 1992, pp. 448-452.

${ }^{3}$ A. Ciaconius, Historiae Pontificum Romanorum et S.R.E. Cardinalium, II, Romae 1677, cols. 649-650. Si se excluye a un Pedro Hispano, cardenal-obispo de Sabina entre el 1302 y el 1310, no existe en el s. XIV ningún cardenal español con ese nombre ni en la Curia de Aviñón ni en la romana (Diccionario de historia eclesiástica de España I, 1972, s.v. Cardenales Españoles, p. 347). No obstante, la errónea identificación de Hermanin ha sido acogida tanto por la historiografía local (A. Accrocca, Cori. Storia e monumenti, Roma 1933, p. 104; E. Scarnicchia, Cori attraverso i secoli, Cori 1968, pp. 48-49) como por todos los autores que se han interesado posteriormente por las pinturas del oratorio (H. L. Kessler, art.cit., p. 62), si bien en el caso de S. Romano dicha identificación es aceptada con muchas reservas (op.cit., p. 451).

${ }^{4}$ Únicamente R. van Marle fechaba también en el segundo cuarto del s. xv las partes más antiguas del ciclo de Cori (op. cit., pp. 394-399).

${ }^{5}$ S. Laurienti, Historia Corana, 1637, fol. 38v, Biblioteca Casanatense de Roma, ms. 4057.
}

$A E A$, LXXVII, 2004, 305, pp. 35 a 57 
campo rojo y bordura de blanco con ocho lobos (Fig. 3) ha contribuido su exacta correspondencia iconográfica con las armas que decoraban el sepulcro del cardenal que en un tiempo se hallaba en el coro de la catedral de Burgos y que se conocía a través de la descripción de Juan Loperráez Corvalán, de finales del s. XVIII ${ }^{6}$.

Pedro Fernández de Frías, un prelado castellano poderoso y rico que las fuentes contemporáneas mencionan a veces con el título de «cardenal de España» ${ }^{7}$, abandonó en 1409 la Curia de Aviñón para establecerse en Italia, participando en mayo de ese mismo año en la asamblea que un grupo de cardenales había convocado en Pisa para intentar resolver el cisma que dividía desde hacía mucho tiempo a la Iglesia Occidental. En aquella ocasión, Fernández de Frías subscribió el decreto de la deposición de ambos pontífices, es decir la del aviñonense Benedicto XIII y la del romano Gregorio XII, mientras que estuvo presente, durante el mes sucesivo, en la elección de un tercer papa, Alejandro V. El cardenal entró a formar parte del entourage más restringido de este último pontífice y su ascenso político se vió marcado, en febrero del 1410, por el pasaje de Roma desde la obediencia a Gregorio XII al partido de Alejandro V, una consecuencia directa del abandono de la ciudad por parte del rey de Nápoles, Ladislao Durazzo, que la ocupaba desde el 1408: en marzo del 1410 fue nombrado vicario pontificio en Roma, cargo que desempeñó al menos hasta 1413 , residiendo de forma estable en aquella ciudad, y el 25 de mayo del mismo año Juan XXIII, el sucesor de Alejandro V, le confirió la autoridad de obispo de la Sabina y de las provincias de Campaña y de Marítima ${ }^{8}$. De este modo, Pedro Fernández de Frías debió estrechar los lazos con la ciudad de Cori durante su mandato, que coincidió tanto con las fases conclusivas del conflicto de Durazzo - que en aquellos años afectó sobre todo al Lacio meridional ${ }^{9}$-, como con la adquisición del status de feudo del Senado y Pueblo de Roma por parte de aquel centro pequeño de la provincia de Marítima, un hecho que la historiografía tradicional fecha en $1410^{10}$. Fue en aquel momento, con

\footnotetext{
${ }^{6}$ Cumpliendo con las disposiciones testamentarias, los restos mortales del cardenal Fernández de Frías (fallecido en Florencia en 1420) fueron transportados a su Castilla natal siendo enterrados inicialmente en el monasterio de los Jerónimos de Espeja (Soria) que él mismo había fundado. En 1430 su cuerpo fue trasladado al coro de la catedral de Burgos, concretamente a la capilla del Salvador (T. López Mata, La Catedral de Burgos, Burgos 1950, pp. 131 y 145) que fue demolida a finales del s. xv para poder edificar la monumental capilla funeraria del condestable Don Pedro Hernández de Velasco. En 1489, contemporáneamente a estas obras, el capítulo de la catedral ordenó la realización de un nuevo monumento sepulcral (J. Goñi Gaztambide, Los españoles en el Concilio de Costanza. Notas biográficas, Madrid-Barcelona 1966, p. 217), exactamente el mismo que J. Loperráez Corvalán pudo admirar en el s. xviI detrás del altar mayor (Descripción histórica del Obispado de Osma con el catálogo de sus prelados I, Madrid 1788, p. 328): «[...] y yace en dicha Catedral a las espaldas del altar mayor en un sepulcro muy decente, donde se ven los escudos de sus armas, que son cinco castillos, y seis perros ó lobos por orla, y el epitafio siguiente:

Aspice quam fragilis vita mortalium sit./Qui pedibus hic teritur Cardinalis Hispaniae fuit./Monasterium de Espeja fundavit./Obiit Florentiae anno MCCCCXXV (sic!)».

${ }^{7}$ Este apelativo, que aparece en la lápida sepulcral, se encuentra también en documentos y crónicas contemporáneas (cfr. Archivo Secreto del Vaticano (ASV), Camera Apostolica, Obligationes et Solutiones 56, fol. $1 r$.; F. Isoldi (ed.), Il Diario Romano di Antonio Pietro dello Schiavo (Rerum Italicarum Scriptores, n.s. XXIV/V), Città di Castello 1917, p. 59).

${ }^{8}$ L. Serrano, Los conversos D. Pablo de Santa Maria y D. Alfonso de Cartagena, Madrid 1942, pp. 34, 41-42 y 90; J. Goñi Gaztambide, op.cit., pp. 207-217; F. Martín Hernández, en Dictionnaire d'histoire et géographie ecclésiastiques XVI, 1967, s.v. Fernández de Frías (Pedro), cols. 1106-1107; R. Aubert, ibid., XIX, 1981, s.v. Frías (Pedro Fernández de), cols. 32-34; vid. especialmente W. Decker, en Dizionario Biografico degli Italiani XLVI, 1996, s.v. Fernández de Frías, Pedro, pp. 347-350. Sobre la ratificación del cardenal Fernández de Frías como vicario de Roma por parte de Juan XXIII en junio del 1410 y sobre la extensión contextual de su autoridad a los territorios de Campaña, Marítima y Sabina, cfr. ASV, Registri Vaticani 340 , fols. 122 r. $-129 v$.

${ }^{9}$ Además de la fuente que constituyen I Diurnali del Duca di Monteleone (M. Manfredi (ed.), en Rerum Italicarum Scriptores, n.s., XXI/V, Bolonia 1958, pp. 78-88), se puede consultar el preciso cuadro histórico que proporciona el ensayo de P. Fedele, «I capitoli della pace fra re Ladislao e Giovanni XXIII», Archivio storico per le province napoletane, XXX (1905), pp. 194-202.

${ }^{10}$ S. Laurienti, op.cit., fol. 29r.; A. Accrocca, op.cit., pp. 26-27. Del texto de Laurenti se deduce que la sumisión de Cori al Senado Romano se produjo poco después de febrero del 1410 cuando el ejército napolitano de Ladislao de Durazzo, que había presidiado también a aquel reducido centro lacial hasta el mes de diciembre del 1409, se retiró de Roma (cfr. G. Moroni, Dizionario di erudizione storico-ecclesiatica da S. Pietro ai nostri giorni, LXXXIX, Venecia 1858, p. 197).
}

AEA, LXXVII, 2004, 305, pp. 35 a 57 
toda probabilidad, cuando el cardenal decidió fundar el oratorio de La Anunciación junto a la ya existente iglesia campestre de San Silvestre ${ }^{11}$, así como iniciar su decoración con pinturas al fresco relativas a un amplio ciclo vetero y neotestamentario que reproduce, incluso en la repetición de algunos tituli que acompañan a los cuarenta episodios del programa pictórico, el ciclo de pinturas de la antigua basílica de San Pedro del Vaticano ${ }^{12}$ en la que el proprio Fernández de Frías desempeñó el cargo de arcipreste desde el 28 de enero del $1412^{13}$. No obstante, la ausencia de información impide esclarecer los motivos que indujeron al cardenal a patrocinar la erección de aquel pequeño edificio de culto, del que no se conoce su estatuto jurídico inicial, lo que habría consentido indagar respecto de su eventual vínculo con otras instituciones locales de carácter posiblemente asistencial, tal y como se podría proponer, quizás, teniendo en cuenta la titulación del oratorio a La Anunciación ya que este tipo de dedicación se encuentra asociado frecuentemente a las capillas integradas en estructuras hospitalarias de finales de la Edad Media ${ }^{14}$. Por otra parte, la primera mención documental del oratorio es de un siglo posterior a su institución puesto que aparece en una acta estipulada ante el notario Antonio Landi el 11 de octubre del 1517, relativa a la asignación del oratorio con la iglesia de San Silvestre a un grupo de monjes, casi todos de origen español, por parte del capítulo de la colegiata local de Santa María ${ }^{15}$.

En cualquier caso, se puede afirmar con seguridad que el cardenal Fernández de Frías no benefició la fundación de Cori a través de un legado testamentario; de hecho no se encuentra ninguna huella en dicho sentido en ese documento del que el archivo capitular de la catedral de Burgos conserva una copia que data del segundo cuarto del s. $\mathrm{Xv}^{16}$. Esto confirmaría indirectamente el hecho de que la construcción del oratorio habría sido ultimada antes del 1420, año de la muerte del cardenal, así como sugiere una fecha posterior a aquella para la inscripción que se halla esculpida en caracteres del gótico tardío en la arquivolta de la portada de entrada (Fig. 2). Un primer motivo de ello reside en el contenido del proprio texto ya que a través de la referencia de DE SPAGNIA FUIT QUI ME LEGERIT DICAT UNU(M) PATER $N(O S T E R) P(R O) A(N) I(M) A M E A$ demuestra que se ha producido ya la defunción del personaje al que está dedicado recurriendo a la formulación de algunos elementos —como el anonimato y el DE SPAGNIA FUIT (que aludiría a su título más que a sus orígenes ibéricos)—que

\footnotetext{
${ }^{11}$ La existencia de la iglesia de San Silvestre se halla atestiguada el 29 de julio de 1273 por el acta de donación a la comunidad eremítica de un huerto para la construcción del convento de San Agustín, situado en las afueras de la puerta Romana «in loco ubi post S(anct)um Sÿlvestrum dicitur»: cfr. el manuscrito de T. Bonasoli, Notitie della Religione Agostiniana e principalmente della Provincia Romana, 1782 ca., p. 384, conservado en Roma en el Archivo General de los Agustinos (AGA).

${ }^{12}$ H. L. Kessler, op.cit., p. 60.

${ }^{13}$ Il Diario Romano..., cit., p. 72.

${ }^{14}$ Dos casos emblemáticos, y cronológicamente cercanos, de capillas de hospitales dedicadas a La Anunciación lo constituyen el oratorio que los Colonna mandaron construir en 1422 en Riofreddo, un reducido centro situado entre el Lacio y los Abruzos (G. Presuti, «I Colonna di Riofreddo», Archivio della società romana di storia patria XXXV (1912), pp. 101132) y la iglesia del hospital de La Anunciación de Nápoles, reconstruida en 1423 por la reina Juana II (G. D’Addosio, Origine vicende progressi della Real S. Casa dell'Annunziata di Napoli (Ospizio dei Trovatelli), Nápoles 1883, pp. 58-59). Según lo que se conoce hasta ahora, en lo que concierne a Cori parece difícil relacionar la capilla de La Anunciación con el hospital de San Quirico, cuya existencia se conoce sólo a través de un Breve de Eugenio IV del 2 de mayo de 1446 en el que se pedía que el conjunto, que se hallaba por entonces en ruinas, fuese reconstruido y se asignase a la comunidad agustiniana que también estaba establecida en la localidad Insito, en las inmediaciones del oratorio fundado por el cardenal Fernández de Frías (ASV, Registri Lateranensi 428, fols. 218r.-218v.).

${ }^{15}$ Archivo de Estado de Latina (ASL), Archivio notarile di Cori, b. 4, prot. 24, fols. $51 v-52 r$. Entre los monjes a los que se asignó el conjunto de La Anunciación y de San Silvestre se mencionan los españoles Girolamo Morano, Pietro Goeli catalán y Giovanni Zamorano junto a Girolamo Lombardo.

${ }^{16}$ Archivo Capitular de la catedral de Burgos, libro 64, fols. $59 r-62 r$ (cfr. D. Mansilla, El archivo capitular de la catedral de Burgos, Burgos 1956, Publicaciones del Seminario Metropolitano de Burgos, serie C, IV, p. 60). Aprovecho la ocasión para agradecer al prof. Juan Nadal Cañellas, delegado de la Embajada de España ante la Santa Sede, que me haya facilitado la obtención de una copia del testamento original.
} 

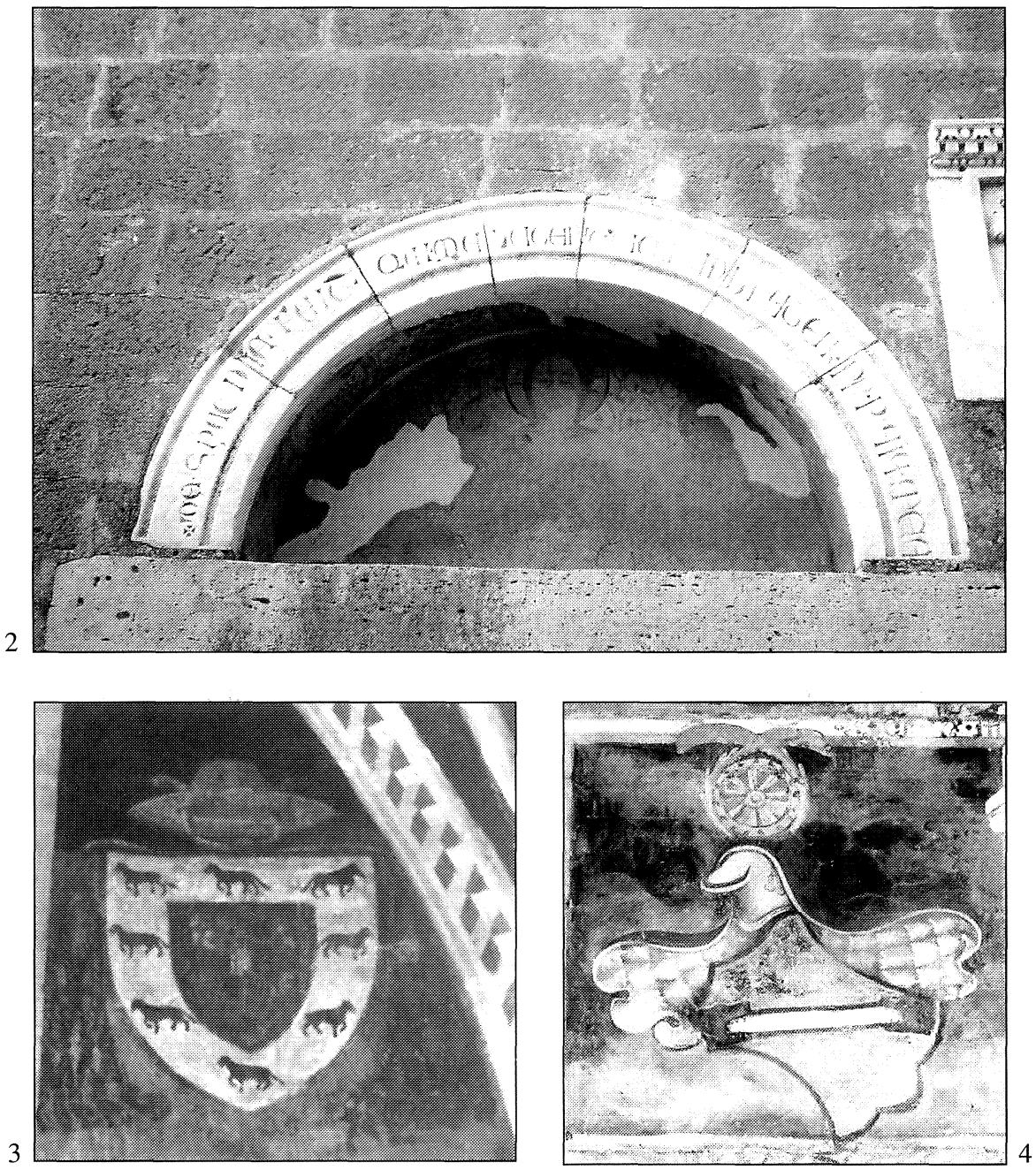

5

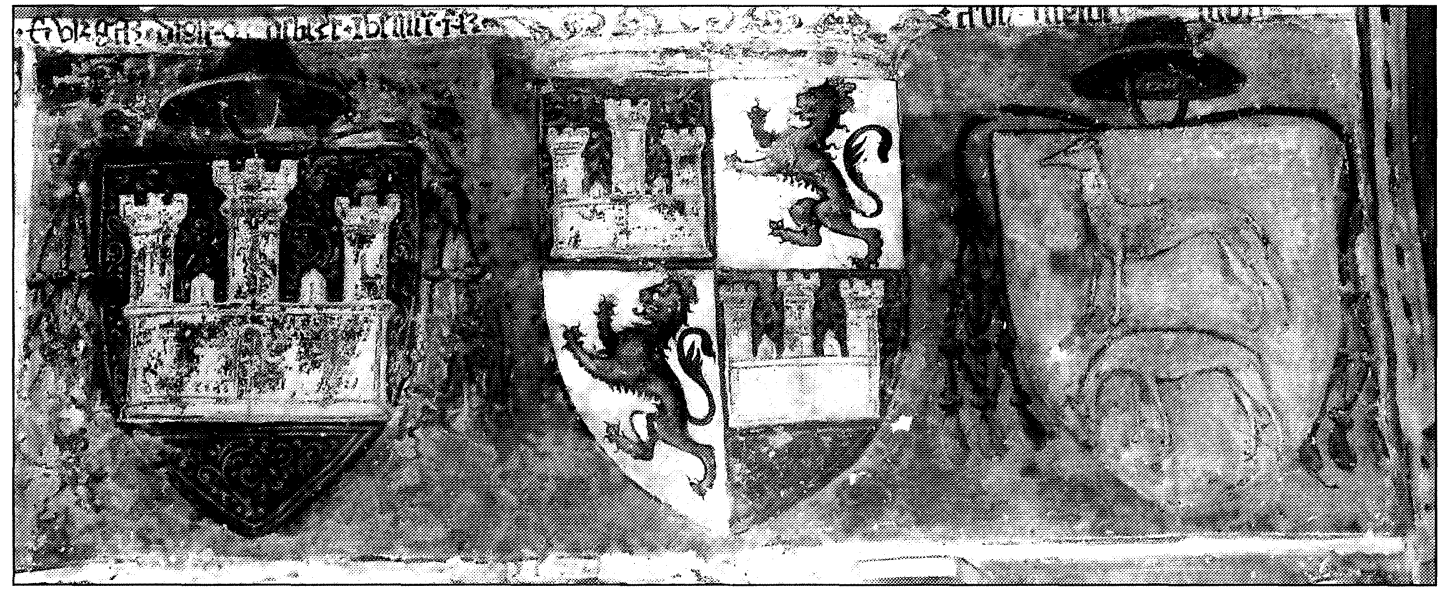

Fig. 2. Cori, Oratorio de La Anunciación, fachada, tímpano de la portada.

Fig. 3. Cori, Oratorio de La Anunciación, pared del altar, escudo del cardenal Pedro Fernández de Frías.

Fig. 4. Cori, Oratorio de La Anunciación, pared lateral, escudo de Juan de Tovar.

Fig. 5. Cori, Oratorio de La Anunciación, pared lateral, escudo de los cardenales Alfonso Carrillo de Albornoz y Juan Cervantes de Lora y de la Corona de Castilla y León.

AEA, LXXVII, 2004, 305, pp. 35 a 57 
se encuentran también en la lápida funeraria de Burgos. La segunda razón es, en cambio, de carácter esencialmente técnico, ya que el elegante epígrafe no se adecúa perfectamente al recorrido semicircular de la cornisa del tímpano, mostrando así una ejecución vacilante que sólo se puede explicar si se acepta que esta haya sido posterior a la construccción de la propria portada.

De esta forma, parece que se pueda atribuir con toda probabilidad la ejecución de la inscripción conmemorativa a los dos influyentes personajes de origen español que se prodigarían, en los años inmediatamente sucesivos, en el proseguimiento del ciclo pictórico del oratorio junto a los ciudadanos y al Municipio de Cori. En efecto, entre mayo de 1426 y marzo de 1434, los cardenales Alfonso Carrillo de Albornoz y Juan Cervantes de Lora encargaron la pintura al fresco de sus armas - un castillo dorado en campo rojo y dos ciervas en campo verde respectivamente- en la pared sudoeste de la capilla junto a las insignias del reino de Castilla y León ${ }^{17}$ (Fig. 5). La presencia del emblema de la casa real, a la que ambos cardenales representaban destacadamente ante la Curia romana, podría atestiguar también el patronazgo jurídico de la Corona sobre el oratorio de Cori. En las siguientes décadas, La Anunciación fue objeto de un continuo trasiego de viajeros hispánicos, tal y como lo demuestran algunas firmas grabadas en la parte inferior de las pinturas y especialmente en la pared del fondo del oratorio junto al altar de pared, entre las que destaca la de un Joh(an)n(e)s Ortiz ispanus clericus palentinus ${ }^{18}$. Se desconoce, por el momento, la razón de esta perseverante presencia de individuos españoles entre los patrocinadores y los visitantes del oratorio, pero es evidente que el nombramiento del cardenal Cervantes de Lora como obispo de Ostia y Velletri entre el 1446 y el 1453 — diócesis a la que pertenecía Cori- podría haber consolidado esta vinculación con La Anunciación ${ }^{19}$. En cualquier caso, la relación con España se halla circunscrita a un área geográfica concreta de Castilla, es decir la correspondiente a las diócesis contiguas de Osma y de Sigüenza. Fernández de Frías y Carrillo de Albornoz habían sido durante mucho tiempo el obispo y el administrador, respectivamente, de la primera diócesis, mientras que la diócesis de Sigüenza tuvo como obispo a este último entre el 1422 y el 1434 , año de su muerte ${ }^{20}$. Esta precisa localización de los benefactores hispanos se halla confirmada también por la pintura al fresco del escudo de un miembro de la casa de Tovar (Fig. 4), que presenta la efigie de la rueda de Santa Catalina de Alejandría, patrona de Berlanga de Duero, un importante centro, en aquella época, de la diócesis de Sigüenza que se hallaba precisamente bajo el señorío de los Tovar desde el $1370^{21}$. A pesar de que la ilegibilidad de la inscripción que aparece al lado del

\footnotetext{
${ }^{17}$ La cronología relativa al patrocinio de los dos prestigiosos prelados españoles a favor del oratorio de La Anunciación se ciñe a las fechas del 24 de mayo de 1426, día en que Cervantes de Lora fue elevado al cardenalato y a la del 14 de marzo de 1434, fecha en que Carrillo de Albornoz murió (cfr. F. Pérez, en Dictionnaire d' histoire et géographie ecclésiastiques, XII, 1953, s.v. Cervantes de Lora (Juan), cols. 179-180; A. Strnad, en Dizionario Biografico degli Italiani, XX, 1977, s.v. Carrillo de Albornoz, Alfonso, pp. 753-758). A este respecto hay que notar que en el manuscrito de Laurienti, en el que por otra parte no se identifican los cardenales españoles que intervinieron en la decoración pictórica de la capilla, se afirma también que «[...] antiques pictures pictis circa annum D(omi)ni 1426, sicut quaedam Cardinalium insignia cognosci potest, vetus, ac novum Testamentum pictum est [...]» (Historia Corana, cit., fol. $38 \mathrm{v}$.).

${ }^{18} \mathrm{~F}$. Hermanin ya había notado la presencia de estos grafitos grabados en el revoque «in gotica corsiva spagnola» siendo el más antiguo - entre los que adjuntan una fecha- el que se remonta al 1455 (Le piture della cappella, cit., p. 50).

${ }^{19}$ F. Pérez, en op.cit., s.v. Cervantes de Lora (Juan), cols. 179-180; no obstante, la diócesis de Ostia y Velletri sería administrada por el vicario Pedro Cervantes, pariente del cardenal y arcediano de Brunete, tal y como se deduce de un documento fechado el 24 de agosto de 1448 (cfr. G. Caetani, Regesta Chartarum. Varia (Documentos del Archivo Caetani), Ciudad del Vaticano 1936, doc. C. 703, pp. 140-141).

${ }^{20}$ Fernández de Frías desempeñó el cargo de obispo de El Burgo de Osma desde el 1379 al 1404, mientras que en 1408 la administración de la diócesis pasó a Carrillo de Albornoz, que la conservó hasta el 1422, fecha en que fue nombrado obispo de Sigüenza (cfr. V. Strnad, en op.cit., s.v. Carrillo de Albornoz, pp. 753-754; W. Decker, en op.cit., s.v. Fernández de Frías, p. 347).

${ }^{21}$ Sobre la identificación del emblema pintado en La Anunciación de Cori (si bien sus colores se han visto alterados considerablemente por el transcurso del tiempo y también por recientes trabajos de restauración) con el escudo de la casa
} 
emblema nos impide precisar la identidad del personaje, los atributos que adornan el escudo heráldico, es decir el emblema de la ciudad y la cimera con lambrequín, permiten identificarlo con Juan de Tovar, fundador del mayorazgo de Berlanga en 1430. Tras rebelarse al rey de Castilla, Juan II, en 1435, Juan de Tovar debió de refugiarse en el sur de Italia, y concretamente en Campania ya que un homónimo se halla documentado, efectivamente, en cuanto hombre de armas asoldado por Alfonso V de Aragón entre enero y octubre de 1441, es decir durante los meses que precedieron a la conquista de Nápoles por los aragoneses ${ }^{22}$.

De este modo, el cuadro histórico que se perfila hace variar, pues, la cronología del monumento situándola en la primera mitad del s. xv. Para la construcción del oratorio se eligió un área del condado que poseía una posición estratégica junto a la vía principal de comunicación que pasaba por Cori ${ }^{23}$ y que contaba ya con otras presencias religiosas importantes como la pequeña iglesia campestre de San Silvestre y, especialmente, el convento eremítico de San Agustín, que se halla atestiguado documentalmente a partir del $1273^{24}$. Actualmente, el oratorio de La Anunciación se sitúa todavía en los límites de una plataforma estrecha sobre una colina desde la que domina, a poquísima distancia, la vía que procede de Cisterna cuyo trazado, que en este punto es rectilíneo y ligeramente ascendente, reproduce exactamente el recorrido antiguo. Dada la naturaleza del terreno, el edificio se implantó sobre una sólida plataforma de cemento que, además de aprovechar los cimientos de un monumento romano precedente, contiene una cisterna de reducidas dimensiones y de forma rectangular que se halla cubierta con una bóveda de cuarto de cañón. A través de una puerta adintelada, situada en el exterior de la pared del fondo del oratorio, se accedía al interior de aquel depósito hídrico excavado en el espacio situado debajo de la zona del altar y al que era conducida el agua pluvial recogida del techo de la capilla mediante un conducto de terracota alojado en el muro. Desde el punto de vista arquitectónico, el edificio, de pequeñas dimensiones, posee una planta rectangular que desarrolla en su interior casi ocho metros de largo por cuatro de ancho. Los espesos muros perimetrales llevan aparejados en los laterales una serie de contrafuertes sobre plinto perfectamente adosados al paramento mediante dentellones; dichos contrafuertes alcanzan una cota ligeramente inferior a la que llegan los muros longitudinales y se corresponde con el punto de imposta de la bóveda de cañón que cubre, con una leve tendencia ojival, el vano de culto al que originalmente se accedía únicamente desde la portada colocada en el lado sudoeste. La débil iluminación del oratorio es regulada por dos ventanas de un solo vano y enmarcadas por

de Tovar, que se compone de una banda de oro engolada en cabezas de dragón sobre campo azul, se remite a los trabajos de heráldica española de A. y A. García Carraffa (Enciclopedia heráldica y genealógica hispano-americana, LXXXV, 1962, pp. 166-167) y de M. Popoff ( L' héraldique espagnole et catalane à la fin du Moyen-Age, Documents d' héraldique, 5 , París 1989, p. 14). Dicha identificación se halla confirmada también por los numerosos emblemas que se encuentran en la colegiata y en los muros del castillo de Berlanga de Duero (cfr. S. Andrés Ordax (ed.), Castilla y León/l (La España gótica, 9), Madrid 1989, pp. 380-393).

${ }^{22}$ Frammenti di cedole della Tesoreria di Alfonso I (1437-1454), en Fonti Aragonesi (Testi e documenti di storia napoletana publicados por la Accademia Pontaniana), Archivisti Napoletani (ed.) I, Nápoles 1957, pp. 109 (fol. 39,21 de enero de 1441) y 113 (fol. 42, 22 de octubre de 1441). Nuestro Juan de Tovar podría ser identificado quizás con un Giovanni di Tonar mencionado en un trabajo de C. Minieri Riccio («Alcuni fatti di Alfonso I di Aragona dal 15 aprile 1437 al 31 di maggio 1458», Archivio storico per le province napoletane VI (1881), pp. 22 y 24) del que se recuerda que el 18 de junio de 1439 y el 14 de octubre de 1441 se hallaba bajo el mando de Alfonso en cuanto capitán de los sacomanos y hombre de confianza del soberano ya que lo utilizó también «para misiones secretas». Para las escasas y fragmentarias noticias sobre los miembros de la familia de Tovar que vivieron durante el s. xv, véanse M. T. de la Peña Marazuela, P. León Tello, Archivo de los Duques de Frías I, casa de Velasco, Madrid 1955, p. 43, A. y A. García Carraffa, op.cit., pp. 156-157 y E. Cooper, Castillos señoriales de Castilla de los siglos xV y XVI, II, Madrid 1980, p. 844.

${ }^{23}$ Según P. Brandizzi Vittucci, la vía que partía desde la puerta situada junto a la torre llamada «Torricello» conectaba directamente la población de Cori con el oratorio de La Anunciación y hasta 1708 el ermitaño que residía en aquella era «el único que podía exigir a los transeúntes la gabela a perjuicio del municipio de Cori ya que aquel se quedaba con tales ingresos» (Cora. Forma Italiae. Regio I- Volumen quintum, Roma 1968, p. 39).

${ }^{24}$ Cfr. supra nota 11.

$A E A$, LXXVII, 2004, 305, pp. 35 a 57 
lastras reutilizadas de marmol y de travertino; ambas ventanas, que son diferentes en su exterior en cuanto a diseño y dimensión, se asoman al lado sudoeste y alternan con los contrafuertes, mientras que una tercera pilastra, de aspecto semejante, se halla adosada a la pared opuesta del edificio, aun cuando hoy sólo se aprecie fundamentalmente el basamento, ya que ha sido englobada en el muro noroccidental de la sacristía del s. XVII. Las estructuras parietales muestran un aparejo lapídeo pseudoisódomo, compuesto por bloques de caliza y de toba volcánica bien escuadrados según un módulo bastante regular, calculable en torno a los 20-21 centímetros y constituido la mayoría de las veces por sillares de tamaño mediano presentando unas medidas que oscilan, de todas formas, entre los 20 y los 48 centímetros de largo. Este tipo de aparejo se puede comparar con los sistemas de construcción utilizados en algunas construcciones romanas que se hallaban en obras durante el primer tercio del s. XV. De hecho, la torre de Martín V del palacio Senatorial en el Campidoglio (del 1427 aprox.) representa un paralelo adecuado que confirma la reciente propuesta de Daniela Esposito a propósito de la influencia que los modelos romanos ejercieron, incluso a finales de la Edad Media, sobre los talleres activos en el Districtus Urbis ${ }^{25}$.

En el caso de La Anunciación de Cori parece evidente la alta calidad de la manufactura arquitectónica que podía competir, incluso, con las construcciones romanas contemporáneas patrocinadas por cardenales y pontífices. Esto se manifiesta también en la contraposición material y cromática establecida entre la zona del basamento, alzada con hiladas de caliza (a excepción de la fachada), y el alzado del resto del edificio donde se yuxtaponen hiladas de toba de color amarillento. Estas hiladas se interrumpen muy por debajo de la línea actual del alero, lo que demuestra que el oratorio poseía originariamente un alzado más reducido y una cubierta a dos aguas. La consistente y ulterior elevación de la construcción, que puede ser atribuida a los trabajos realizados en el s. XVIII, se aprecia especialmente en la fachada ya que en ella se pueden notar todavía las marcas de los modillones del tejado primitivo. El frente se halla connotado por escasos elementos arquitectónicos y ornamentales cualificadores que han perdido, como en el caso de la portada con tímpano semicircular y del emblema del Municipio de Cori, la antigua decoración polícroma a base de teselas musivas que aún acusa el influjo cosmatesco. Encima de la portada, se halla una ménsula empotrada, que quizá servía para sostener una lámpara y, sobre ella, perpendicularmente, un listel de caliza presenta una rama esculpida de olivo que posiblemente alude a la patrona de la ciudad, la mártir Oliva; a esta fase pertenece también el óculo que originariamente existía en el centro del tímpano, si bien la capilla se vio privada inmediatamente de tal fuente de luz pues hacia 1440 se cegó la abertura para realizar la pintura al fresco del Juicio Universal en la pared interior de la fachada ${ }^{26}$.

En definitiva, el oratorio de La Anunciación se configura, tanto desde el punto de vista de su proyectación como también mediante sus pinturas al fresco, en cuanto expresión de una fase de transición. La adhesión a un lenguaje constructivo que manifiestamente pertenece al s. Xv, y que se presenta en el diseño de la fachada a través de una composición que posee ya un aire

\footnotetext{
${ }^{25}$ D. Esposito, Tecniche costruttive murarie medievali. Murature «a tufelli» in area romana, Roma 1997, pp. 33 y 114 Esta estudiosa constata que las construcciones con «tufelli» (NT: bloques en toba volcánica de reducidas dimensiones) sufrieron a lo largo del s. xIV un lento y constante aumento de la altitud de los elementos lapídeos de forma que en el tramo de las murallas situado junto a la puerta del Popolo — atribuido al pontificado de Bonifacio IX (1389-1404) - se llegaría a emplear una serie de bloques de casi 15 centímetros de alto. Esta tendencia al aumento de la altura de los sillares continuó aún en los edificios de la primera mitad del siglo sucesivo, observación que la propia Anunciación de Cori confirma ampliamente. Para la torre de Martín V (1417-1431), véase C. Pietrangeli, «Il Palazzo Senatorio nel Medioevo», Capitolium XXXV (1960) fasc. 10, p. 4; id., «I Palazzi capitolini nel Rinascimento», Il Campidoglio, Roma 1965, p. 25. En cambio, el estudio de R.W. Kennedy, «The contribution of Martin V to the rebuilding of Rome, 1420-1431», The Renaissance reconsidered: a symposium, Northampton (Mass.) 1964, Smith College Studies in History, 4, pp. 27-52, no es de ninguna utilidad.

${ }^{26}$ S. Romano, op. cit., p. 452.
} 
proto-renacentista, no significa su renuncia a una articulación mediante contrafuertes laterales, vinculándose aún a una formulación del espacio interior que todavía es genuinamente medieval copiando el modelo introducido por primera vez en Roma, en el s. XIII, en la capilla de San Silvestre de la iglesia de los Cuatro Santos Coronados ${ }^{27}$.

El lazo que seguramente existía entre Castilla y el oratorio de Cori se fue extinguiendo a partir del 1517, año en el que el acta notarial ya mencionada atestiguaba, con ocasión de la mención de la dependencia de la capilla respecto de la colegiata local, que aquellos cuatros ermitaños, de los que tres eran de origen hispano (vid. n. 15), se ocuparían de la celebración del oficio. A partir de entonces, no hay ningún elemento artístico, ni ninguna fuente de archivo que documente la relación entre La Anunciación y algún personaje español. La disolución de aquel lazo parece coincidir con el fin de la dinastía aragonesa en el cercano reino de Nápoles y con el paso del sur de Italia a manos de los Habsburgo. De hecho, en 1637, el franciscano Sante Laurienti parece ignorar tanto los orígenes del oratorio como el nombre de los patrocinadores castellanos representados por los escudos, mientras que, por el contrario, conoce perfectamente la contribución que habían ofrecido algunos ciudadanos y el proprio Municipio de Cori para embellecer la capilla a lo largo del s. xv, lo que indica que el recuerdo de aquella presencia forastera se había perdido muy pronto ${ }^{28}$. Este autor proporciona una descripción breve del monumento (del que un ermitaño local se ocupaba por entonces) que confirma su unión con San Silvestre ${ }^{29}$, si bien no hace ninguna alusión a las obras de reconstrucción que una placa empotrada en el exterior de San Silvestre fecha en 1610. Creo que en aquella ocasión se debió realizar la sacristía, que poseería también una función de vestíbulo que conectase ambos edificios de culto, así como se habría abierto la puerta con arquitrabe en la pared nordeste del oratorio destruyéndose, así, una de las composiciones pictóricas de mayor nivel. Encima del vano cuadrado de la sacristía, se recabó también un segundo ambiente, que probablemente constituiría la celda para el monje, al que se llegaba a través de un profferlo* adosado al flanco occidental de la iglesia de San Silvestre que fue dotada, por ese mismo lado, de una entrada independiente.

En la tercera década del s. xviII, el oratorio de La Anunciación y la iglesia comunicante de San Silvestre aún sufrirían una consistente reestructuración patrocinada por Pietro Prence, camarlengo del capítulo de la colegiata, tal y como lo atestiguan dos inscipciones en las que aparecen las fechas de 1726 y de $1730{ }^{30}$. En 1726 se erigió, efectivamente, la torre del campanario junto a la esquina sudeste del conjunto y a su lado se construyó una residencia más confortable para el monje. Actualmente, de esta nueva ermita sólo se conservan las estructuras de su perímetro que acabaron por incorporar en el lado sudoeste un tramo de muro más antiguo y dotado de una entrada obstruida que era, quizá, una parte del edificio construida en 1610 y posteriormente destruida a causa de los trabajos patrocinados por Prence. En 1730 el camarlengo encargó también la modificación estructural del interior de la pequeña iglesia de San Silvestre de forma que el conjunto medieval de una sola nave con ábside fue reelaborado, do-

\footnotetext{
${ }^{27}$ A. Muñoz, Il restauro della chiesa e del chiostro dei SS. Quattro Coronati, Roma 1914, pp. 103-121; P.F. Pistilli, «L'architettura tra il 1198 e il 1254», en A.M. Romanini (ed.), Roma nel Duecento. L' arte nella città dei papi da Innocenzo III a Bonifacio VIII, Turín 1991, pp. 64-66.

${ }^{28}$ S. Laurienti, op.cit., fol. $38 v$.

${ }^{29}$ Ibidem, fol. $38 v$.

* NT.-Escalera exterior típica de la arquitectura civil del Lacio en la Edad Media.

${ }^{30}$ Actualmente se conserva solamente la inscripción del 1726 que se halla empotrada en la pared externa del campanario adosado a la ermita del s. XviII. El otro epígrafe, fechado en 1730, que se halla colocado en el interior de la capilla del Crucifijo, ha sido robado recientemente, si bien se conoce su contenido gracias a una foto conservada en el Archivo de Latina de la Soprintendenza ai Beni Architettonici e Ambientali per il Lazio. El texto de las dos inscripciones recita así: PETRUS PRENCE CAMERARIUS EX PIIS ELEMOSINIS AEDIFICAVIT 1726; PETRUS PRENCE CAMERARIUS EX PIA CHARITATE F(IERI) F(ECIT) ANNO D(OMI)NI MDCCXXX.
}

$A E A$, LXXVII, 2004, 305, pp. 35 a 57 
tándole de un actualizado aspecto barroco con la anexión de un vano cuadrado, de reducidas dimensiones, en el lado oriental; con gran probabilidad, fue entonces cuando el edificio de culto cambió su dedicación convirtiéndose en la capilla del Crucifijo por el tema de la pintura al fresco del gótico tardío que se había descubierto en la pared meridional ${ }^{31}$ y que fue enmarcado en un altar moderno. Las obras llevadas a cabo en el s. XVIII afectaron también al oratorio de La Anunciación provocando la elevación de sus muros para crear un ambiente debajo del techo, que no se podría utilizar, aun cuando se hallase ventilado por estrechas ventanas de un solo vano de forma que permitiese la eliminación de las filtraciones de agua. El objetivo de tal operación consistía en salvaguardar lo que había sobrevivido del ciclo pictórico testamentario situado en el intradós de la bóveda, y que seguramente se hallaba muy deteriorado por la humedad, pero a pesar de ello no pudo impedir que una serie de artistas de escasa destreza retocasen la totalidad de los episodios (en aquella misma ocasión, con gran verosimilitud), eliminando así, y para siempre, una gran parte de la obra del primer artista de los frescos de La Anunciación encargados por el cardenal Fernández de Frías en la segunda década del s. Xv.

\section{Las pinturas al fresco}

La decoración del oratorio de La Anunciación de Cori fue descubierta en 1906 por Federico Hermanin y su revelación constituyó inmediatamente uno de los mayores capítulos de la pintura lacial del s. $\mathrm{xv}^{32}$. Los frescos se extienden por la totalidad de la superficie de las paredes y de la bóveda según una disposición por registros y representan una serie de historias del Viejo y del Nuevo Testamento encuadradas por esbeltas columnitas: en la pared del altar se halla la escena epónima del Anuncio a María, así como historias sobre la Infancia de Cristo (la Adoración de los Magos y de los Pastores; Fig. 6) y a continuación, según un orden de lectura que inicia en la bóveda (Fig. 7) y pasa a los registros superiores de las paredes longitudinales, se colocan las Historias del Génesis y del Éxodo hasta Moisés; en la pared opuesta sigue el ciclo cristológico de la Pasión, que se concluye en los registros inferiores con la Resurrección y con el Cristo en el limbo y al que siguen las figuras de los Santos y de los Apóstoles y dos Vírgenes entronizadas con el Niño en el lado opuesto. En la pared interior correspondiente a la fachada se halla la gran pintura al fresco del Juicio Universal (Fig. 8) que se sitúa sobre dos parejas de santos colocadas a ambos lados de la portada de entrada. La documentación de la capilla se halla enriquecida nada menos que con cinco escudos y numerosas inscripciones pintadas y grafitos.

En el estudio de Hermanin ya se hacía referencia a la Historia corana del menor Sante Laurienti, la única fuente histórica local —escrita en 1637-que proporcionaba algunas anotaciones importantes sobre La Anunciación ${ }^{33}$. Allí se recordaba que el oratorio estaba dotado de antiquis picturis pictis circa annum dni. 1426, fecha que se deducía de uno de los emblemas cardenalicios, sicut per quedam cardinalium insignia conosci potest, vetus ac novum testamentum pictum est. A continuación se mencionaba la inscripción pintada que era visible todavía, si bien parcialmente, en el escalón del trono de la Virgen en la escena de la Adoración de los Magos, en la pared del altar, donde aparece inscrito el nombre de la mujer que había realizado el encargo, Ista figura Virginis M(aria)e fecit fieri Catharina Stephanelli. En una

\footnotetext{
${ }^{31}$ S. Laurienti no menciona la existencia de esta pintura al fresco en San Silvestre, pues en aquel tiempo se hallaba probablemente cubierta por el revoque; es más, este autor afirma que la antigua iglesia, a la que se refiere utilizando aún la antigua denominación, «in parietibus nonnullae perspinciuntur antiquissimae picturae» (Historia Corana, cit., fol. 38v.).

${ }^{32}$ F. Hermanin, op. cit.

${ }^{33}$ S. Laurienti, op. cit.
} 

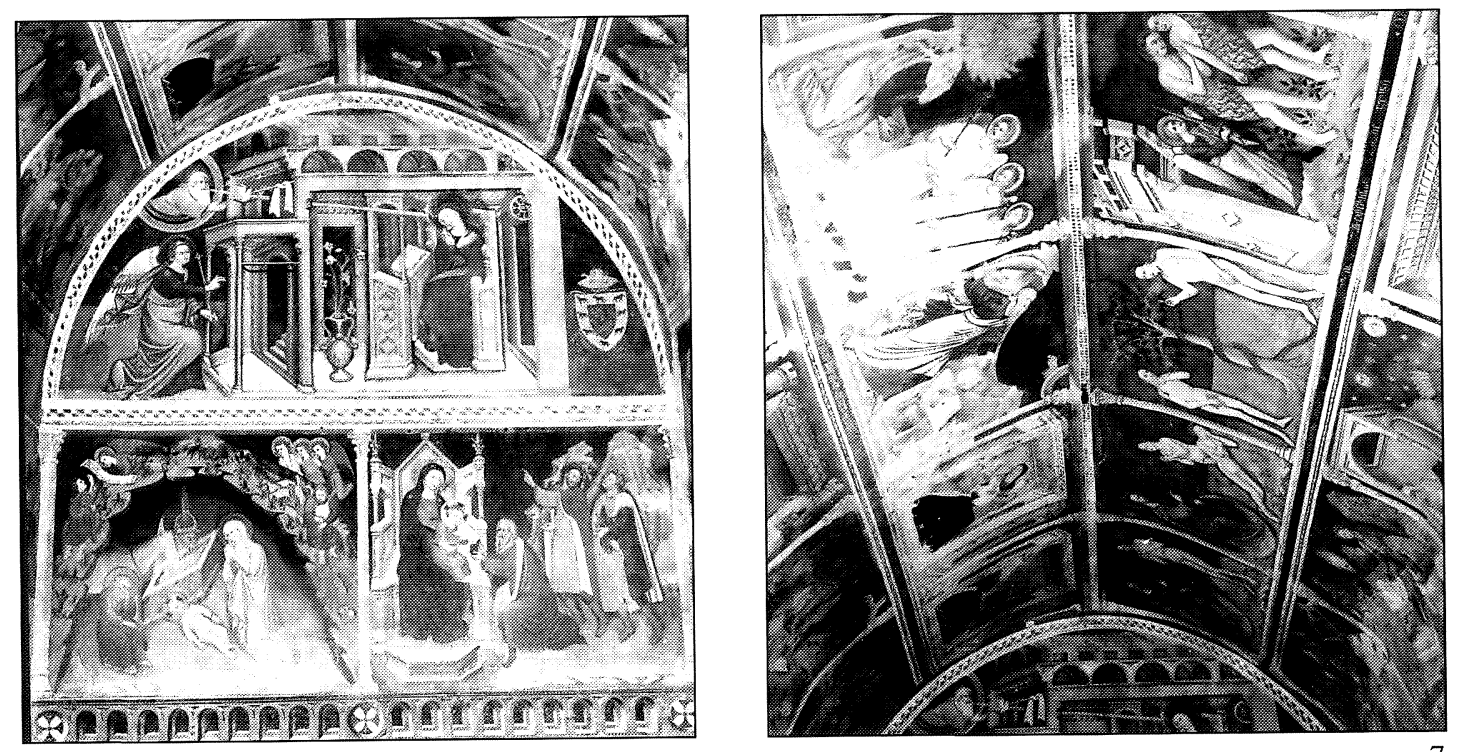

6

8

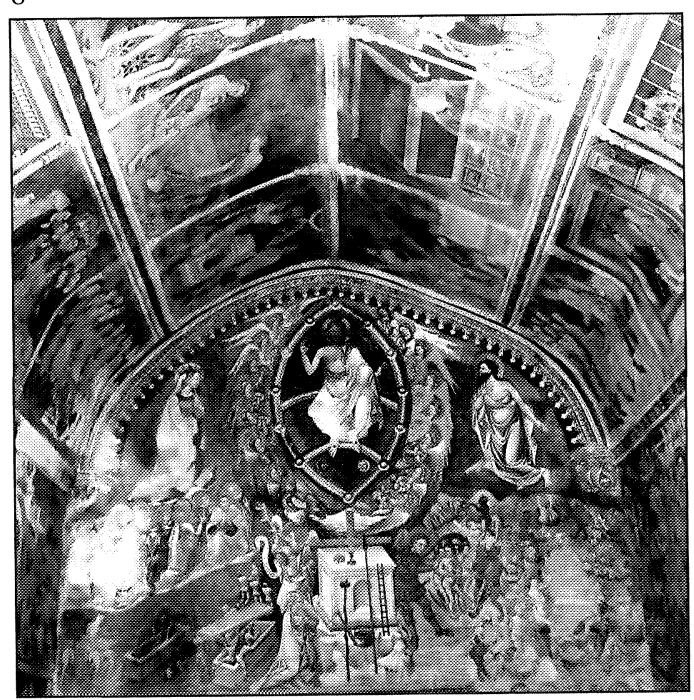

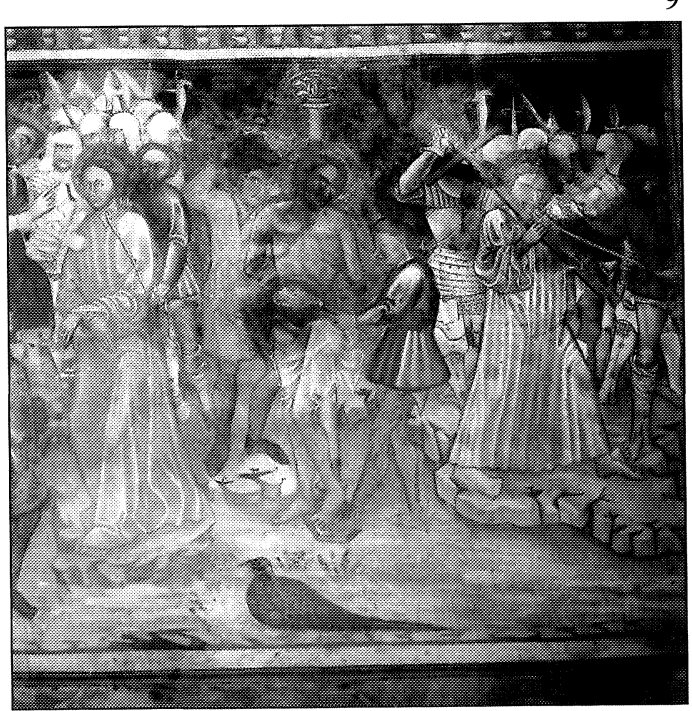

Fig. 6. Cori, Oratorio de La Anunciación, pared del altar, Primer maestro, Anunciación, Adoración.

Fig. 7. Cori, Oratorio de La Anunciación, bóveda, Primer maestro, Historias del Antiguo Testamento.

Fig. 8. Cori, Oratorio de La Anunciación, pared interior de la fachada, Pietro Coleberti y ayudantes, Juicio Universal. Fig. 9. Cori, Oratorio de La Anunciación, pared lateral, Ayudante de Coleberti, Flagelación y Camino del Calvario.

AEA, LXXVII, 2004, 305, pp. 35 a 57 
segunda inscripción, que se refiere al patrocinio del Municipio de Cori, y que el texto de Hermanin daba por desaparecida aunque en realidad se puede ver parcialmente todavía debajo de la representación de la Puerta del Paraíso ${ }^{34}$, en el extremo derecho del registro medio de la pared de la derecha, se lee con cierta dificultad: Hoc opus fieri fecit Commune terre Core. En otro pasaje de la Historia, que es ignorado por Hermanin, se menciona a Stefano Stallione, ciudadano de Cori que vixit circa annum 1422 e identificable con el donante que se halla representado junto a su esposa, arrodillado ante los pies de la Virgen entronizada que se encuentra en el centro del registro inferior de la pared de la izquierda, ya que figura allí el nombre (de forma legible todavía) en la cartela correspondiente ${ }^{35}$.

Una vez presentados estos datos, Hermanin procedía a un análisis histórico con el que trataba de individuar a los diversos patrocinadores que habían contribuido à realizar, en épocas sucesivas y contiguas, la compleja decoración pictórica del oratorio. Según su reconstrucción, el escudo cardenalicio colocado en la pared del altar correspondía al del cardenal Pietro Ispano, creado por Urbano VI en 1378, aun cuando no existiese a este respecto ninguna noticia ulterior a la genérica cita de Ciacconio ${ }^{36}$. El patrocinio español y la asidua frecuentación por parte de prelados castellanos se hallan ampliamente documentados también a través de los numerosos grafitos que han dejado en las paredes y que el proprio Hermanin recordaba destacando su constante referencia a Palencia, precisamente la ciudad de la que el cardenal Pietro resultaba ser obispo: así aparece grabado el nombre de Johannes Ortiz ispaniensi que se califica en cuanto clericus palentinus, a la izquierda del altar, mientras que en otro caso la inscripción Pallentinoi alude a la visita de un grupo de ciudadanos españoles de aquella ciudad. La persistencia de una tradición castellana se ve confirmada también por la identificación de los otros tres escudos colocados, de forma yuxtapuesta, en el extremo derecho del registro medio de la pared de la izquierda. En el centro se halla el escudo cuartelado con los emblemas de la casa real de Castilla, mientras que a los lados se encuentran los otros dos escudos cardenalicios: uno de ellos, el de la pareja de galgos, había sido identificado por Hermanin como el escudo del cardenal Juan Cervantes, creado por Martino V en 1426 y que desde 1446 hasta 1453, año de su muerte, había sido obispo de la diócesis de Velletri y de Ostia, a la que pertenecía Cori. En torno a la identificación de estos escudos se han concentrado tanto las investigaciones de los historiadores locales como últimamente los estudios de Romano ${ }^{37}$, que identificaba el escudo colocado a la izquierda de las insignias del reino de Castilla en cuanto el emblema de Alfonso Carrillo, cardenal español creado en 1440 por el antipapa Feliz V. La compleja y fundamental identificación de estos signa ha sido recientemente resuelta por Pisti$1 \mathrm{li}{ }^{38}$. El escudo considerado como el de mayor antigüedad, y que había sido referido inicialmente al cardenal Pietro Hispano, constituye en cambio el emblema de Pedro Fernández de Frías, cardenal español que pertenecía a uno de los linajes castellanos de mayor nobleza. Nombrado cardenal en 1394, desempeñó un papel político preponderante y hacia el 1411-1412 se halla documentada su presencia en Roma, ciudad en la que recibió una serie de cargos y prebendas. Hacia esos años es precisamente, por tanto, cuando se puede situar el encargo de este oratorio que, por otra parte, establece el comienzo de una tradición de devoción castellana en

\footnotetext{
${ }^{34}$ S. Romano, op. cit., p. 451. El estudio de esta autora, que es fundamental y conclusivo, presenta una omisible confusión en la parte relativa a los frescos de Cori —que deriva del estudio de Hermanin (op. cit.) — entre la inscripción concerniente al misterioso terciario Rem[...]inus, situada junto a la representación de la Piedad a la izquierda del altar, y el recuerdo del patrocinio del Municipio de Cori que se halla, por el contrario, debajo de la representación de la Puerta del Paraíso.

${ }^{35} \mathrm{~S}$. Laurienti, op. cit., fols. $112 r$. e $v$.

${ }^{36}$ S. Romano, op. cit., p. 451.

${ }^{37}$ Ibidem.

${ }^{38}$ P. F. Pistilli: vid. en el precedente estudio relativo a la historia de la arquitectura del oratorio de Cori.
}

AEA, LXXVII, 2004, 305, pp. 35 a 57 
Cori, tal y como lo atestiguan también los otros escudos cardenalicios. Respecto de ellos se puede afirmar que Hermanin había individuado correctamente el que representaba a los dos galgos en cuanto referencia heráldica al cardenal Juan Cervantes de Lora, mientras que para el tercer escudo es preferible indicar, respecto a la tesis de Romano, la representación del emblema del cardenal Alfonso Carrillo de Albornoz, vinculado igualmente a la nobleza castellana de mayor rango, que había sido elegido cardenal en 1408 y que desde 1424 se hallaba en Roma en cuanto figura política relevante dentro de la Curia. Su atestiguada relación precisamente con el cardenal Cervantes (ya que llegará a ser uno de sus albaceas testamentarios) permiten suponer que Carrillo de Albornoz, que será recordado como uno de los hombres más ricos de la Iglesia, fuese el pródigo patrocinador de una parte de la decoración del oratorio de La Anunciación de Cori de forma que la fecha de su muerte, en 1434, podría representar un elemento cronológico post quem de la segunda fase de la ornamentación pictórica. Su realización fue seguida probablemente de forma personal por su amigo y responsable de su testamento, el cardenal Cervantes, representado por el emblema contiguo, que había sido elevado a príncipe de la iglesia en 1426; este dato también constituye un punto de referencia post quem seguro para la datación de la segunda fase de la decoración pictórica.

En el centro del registro medio de la pared de la izquierda se halla pintado un cuarto escudo, que no ha sido considerado por los estudiosos, que presenta unas dimensiones mayores respecto de los otros escudos y que, probablemente, representa la última fase decorativa de la capilla vinculada al patronazgo castellano: sobre un forro de armiño, coronado a su vez por una cimera, se sitúa una columna que engullen dos lobos, y más arriba se representa una rueda dentada entre dos palmas entrecruzadas; tal y como el proprio Pistilli ha identificado también, se trata del blasón de la casa de Tovar, asimismo de origen castellano, que incluía en la parte superior del mismo el emblema de la ciudad de procedencia de la familia, es decir Berlanga de Duero; la probable referencia, según ha sugerido Pistilli, a Juan de Tovar, que se halla documentado en la corte napolitana aragonesa en el 1441, permite afirmar que la última fase de esta empresa decorativa se halla ligada también al encargo de un personaje español siguiendo, así, una tradición relativa a este edificio que se había consolidado en Cori hasta casi la mitad del s. $\mathrm{XV}^{39}$. Los diversos patrocinios ritman la análoga sucesión de los distintos artistas que realizaron la campaña pictórica.

El primer encargo, patrocinado por Fernández de Frías, consistió en la fundación de la capilla hacia principios de la segunda década del s. xv, así como en la definición del programa iconográfico relativo a las pinturas al fresco de la bóveda y de los registros superiores de las paredes laterales. Esta parte de la decoración, que posee un contenido estilístico coherente, debe atribuirse a un maestro lacial mediocre de cultura úmbrica, tal y como Romano ha señalado ya, si bien su actividad deba ser restrasada respecto a cuanto dicha estudiosa afirma, por el contrario, teniendo en cuenta los datos biográficos del cardenal de Frías que sugieren su ubicación en la segunda década del s. xv. Durante esta primera fase se realizó la mayor parte de las historias del Viejo Testamento y, a este respecto, hay que destacar que diversos estudios han considerado la iconografía que presenta el oratorio de Cori en cuanto representante de una de las versiones más importantes de la perdida decoración pictórica de la nave de la basílica medieval de San Pedro del Vaticano ${ }^{40}$. Ahora se puede justificar una referencia semejante a la decoración vaticana a través del patronazgo ejercido por el cardenal Fernández de Frías ya que era, precisamente en 1410, el titular del arciprestazgo de San Pedro. Precisamente el deseo de reproducir la

\footnotetext{
${ }^{39}$ Ibidem.

${ }^{40}$ El estudio más importante sobre el argumento es el de Kessler (op.cit.) que considera el ciclo de Cori como una de las reproducciones más fieles e importantes de la perdida decoración medieval vaticana.
}

AEA, LXXVII, 2004, 305, pp. 35 a 57 
decoración monumental de la nave de la basílica vaticana en los angostos límites espaciales del oratorio provincial provocó que el relato de las historias bíblicas se concentrase también en la bóveda; sin embargo, los temas narrados, la sucesión de las historias separadas por pequeñas columnas, la contraposición ideológica entre los episodios mosaicos y el ciclo cristológico y la representación de los Apóstoles, de cuerpo entero, en un registro diverso reflejan fielmente el relevante modelo vaticano en el que el cardenal español quiso inspirarse incluso en cuanto posible referencia a su prestigioso título. El primer maestro de Cori, que se analiza con gran dificultad por la alteración de todos los rasgos estilísticos de la representación causada por las pinturas posteriores, se puede enlazar con esa amplia corriente de autores de cultura úmbrica que trabajaban también en el Lacio desde la segunda mitad del s. XIV, si bien cabe situar su actividad a principios de la segunda década del $\mathrm{s}$. Xv o, en todo caso, no mucho después de la fecha del fallecimiento del cardenal patrocinador (1420). El programa, que quizás se vió interrumpido por la muerte del cardenal Fernández de Frías, fue completado por otro maestro que inició su actividad pintando las historias de Moisés para pasar sucesivamente a la ejecución de la escena del Juicio en la pared interior de la fachada, que sería terminada por un estrecho colaborador que debió realizar la representación del Arcángel San Miguel y de las penas del Infierno, así como los cuatro santos del registro inferior, para completar después la decoración de la pared contigua con las historias cristológicas: La Oración en el Huerto, el Prendimiento (Fig. 10), la Flagelación (Fig. 9) y la Subida al Calvario, colocando en el registro inferior la representación de San Jerónimo con el león, San Francisco con los estigmas, San Antonio Abad y la Virgen en el trono con los esposos Stallione. Esta segunda fase de la decoración del oratorio de La Anunciación, cuyo calidad pictórica es manifiestamente superior, corresponde probablemente al patronazgo del Municipio de Cori y de los cardenales Carrillo y Cervantes. La neta variación estilística, claramente visible en la escena de Moisés con Aarón que transforma las varas en serpientes (Fig. 11), corresponde al segundo recuadro del registro medio de la pared de la izquierda cerca ya del altar. Aunque las pinturas que se han superpuesto posteriormente dificultan también el análisis de esta parte de las historias del Antiguo Testamento, se puede sugerir como hipótesis para la identificación de este segundo maestro que pueda tratarse del mayor talento pictórico de la región del Lacio meridional de aquellos años, es decir, del maestro Pietro Coleberti de Priverno. La actividad de este pintor se halla atestiguada en 1430 en Roccantica, en la Sabina, aun cuando por su origen se pueda suponer la existencia de otras obras suyas en la región pontina y en concreto en Sermoneta (que dista aproximadamente $10 \mathrm{~km}$ de Cori) en la que se halla documentado efectivamente en torno al 1420. Coleberti pintó allí, según la unánime atribución de los estudios, el tímpano de la portada mayor de la colegiata con la representación de la Virgen con el Niño, San Epafrodito, San Pedro y el Redentor bendiciendo con ángeles en la arquivolta, estableciéndose en aquella ciudad por mucho tiempo tal y como lo atestiguan dos actas notariales, del 1422 y del 1427, estipuladas por cuestiones relativas a esa colegiata, tal y como Cavallaro ha demostrado ${ }^{41}$. Debió ser, pues, en la corte de los Caetani, que en aquellos años había unificado los condados de Fondi y de Sermoneta, donde se concretó la fama de este artista que posteriormente sería llamado por los Bastone de Roccantica para que trabajase, en 1430, en la decoración de la iglesia de familia en sus posesiones sabinas. Y uno de los principales puntos de referencia en la formación de este autor lo constituyó, según Cavallaro ha afirmado de forma convincente, la presencia del Maestro de la Capilla Caldora en la Abadía de Subiaco que hacia principios del s. xv (aproximadamente en torno al 1408) trabajó en las paredes de la iglesia de Santa Escolástica, instaurando un vasto campo de trabajo que se trasla-

\footnotetext{
${ }^{4}$ A. Cavallaro, «Pietro Coleberti di Priverno da Sermoneta (1422) a Roccantica (1430)», en Sermoneta e i Caetani, Atti del Convegno (Roma-Sermoneta, 1993), Roma 1999, pp. 313-327. Se remite a este estudio para una bibliografía completa sobre este pintor del Lacio.
} 

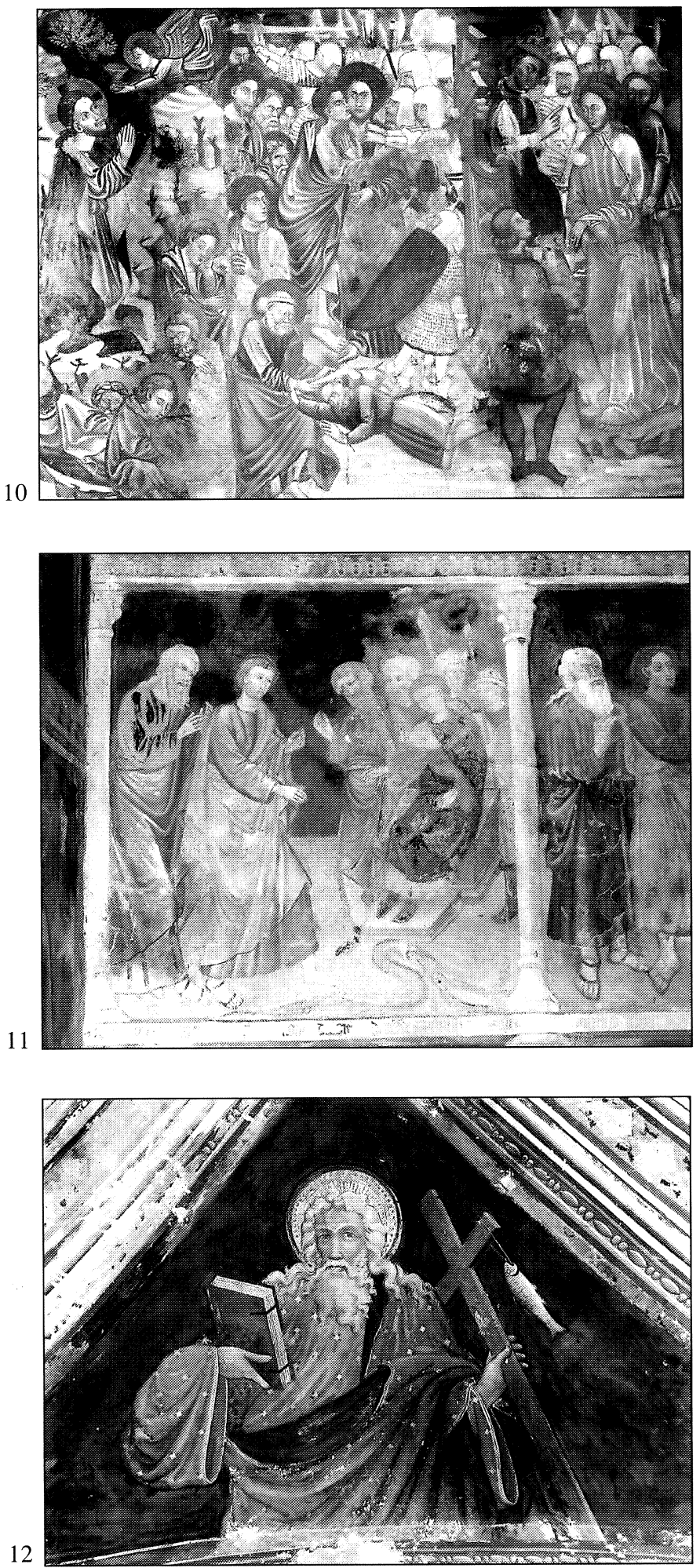

Fig. 10. Cori, Oratorio de La Anunciación, pared lateral, Ayudante de Coleberti, Prendimiento de Cristo.

Fig. 11. Cori, Oratorio de La Anunciación, pared lateral, Primer maestro y Pietro Coleberti, Aarón transforma las varas en serpientes.

Fig. 12. Subiaco, Iglesia de San Benito, paño de la bóveda del crucero, Maestro de la capilla Caldora, S. Andrés.

AEA, LXXVII, 2004, 305, pp. 35 a 57 
daría más tarde a las bóvedas del Sacro Speco con las historias de San Benito (Fig. 12) para completar la decoración que el taller de Conxulus dejó incompleta a mediados del s. xiv. La presencia de esta prestigiosa figura en Subiaco -que se hallaba vinculada al monasterio por otro encargo castellano- supuso un acontecimiento de excepcional relevancia para la pintura lacial del gótico tardío; la vasta extensión de las decoraciones en Subiaco, en las que se nota frecuentemente el descenso del nivel cualitativo, permite sospechar la existencia de un nutrido grupo de ayudantes de taller que tras esta experiencia formativa difundirían en la región los recursos y los rasgos estilísticos que unían una raíz fundamental procedente de Las Marcas con elementos de Umbría y del Lacio. En este ambiente se debió desarrollar la actividad de Pietro Coleberti que, aun considerado por Bellosi ${ }^{42}$ en cuanto el protagonista principal de los trabajos de $\mathrm{Su}-$ biaco, parece que debió ser en cambio, con mayor probabilidad, uno de los posibles jefes de taller que trabajaban en aquellas obras y cuyo éxito personal, en ese ámbito gegráfico cultural escaso en talentos como era el territorio pontino, se halla confirmado por las numerosas decoraciones pictóricas conservadas en la región y que pueden atribuirse directamente a él o a la mayor o menor destreza de sus seguidores. En la misma Sermoneta, además del tímpano de la catedral, se puede asignar también a este pintor la Santa Lucía con el donante (Fig. 13) pintada al fresco en la cripta de la iglesia de San Miguel Arcángel en la que aparecen los caracteres expresionistas, que tradicionalmente se superponen a la frontalidad icónica de la figura, junto a las irregularidades en la realización de las manos y a un cierto refinamiento en el trazado de las esbeltas arquitecturas del gótico tardío ${ }^{43}$, en suma una serie de elementos que aparecen frecuentemente tanto en Cori como en Roccantica. En Sermoneta se halla también, en cuanto índice de la notable huella que había dejado un taller en la producción local, una decoración parietal (en la sala del torreón del castillo Caetani) compuesta por dos parejas de ángeles que sujetan el escudo con los emblemas de aquel linaje y del cardenal Scarampo que propone de nuevo, a comienzos de la segunda mitad del s. xv, los rasgos y los códigos estilísticos que se derivan de la producción de Coleberti, del mismo modo que en la contigua sala de los calabozos (la antigua capilla del castillo) los restos de las pinturas al fresco de los Santos Pedro y Pablo sobre un fondo floreado manifiestan los mismos aspectos figurativos que los acercan también a los santos pintados en las paredes de la capilla de Santa María de Loreto en la iglesia de San Pedro de Fondi (Fig. 14), es decir en otro edificio patronal de los Caetani. Una serie de episodios ligados a Montebuono y a Fianello, en la región sabina, que ya habían sido individuados por Bertini Calosso ${ }^{44}$ y que se pueden situar a mediados de siglo, se pueden referir a colaboradores o a seguidores de Coleberti, como Jacopo de Roccantica o Jacopo de San Polo que dejaron el único testimonio de sus nombres en la decoración del ábside de San Pedro, fechada en 1451, en Montebuono y en la decoración contemporánea de Santa María en Camposanto, en el territorio de Fianello, respectivamente. El carácter tosco e ingenuo que se aprecia en la representación figurativa de estos frescos es semejante al que manifiesta un ayudante de Coleberti en la parte de la derecha del Juicio de La Anunciación de Cori, en las historias de la Pasión, en los cuatro santos que se hallan junto a la portada (Fig. 15), así como en los tres primeros santos y en las Vírgenes del registro inferior de la pared de la izquierda que se distinguen por el relive plano y por un

\footnotetext{
${ }^{42}$ La propuesta de Bellosi sa halla recogida en A. de Marchi, Gentile da Fabriano. Un viaggio nella pittura italiana alla fine del Gotico, Milán 1992, p. 133, n. 71.

${ }^{43}$ El fresco de Sermoneta, que S. Romano recuerda como un «reflejo de la actividad del maestro de la capilla Caldora» $\mathrm{y}$ «poco distante del grupo de obras que ronda la tercera década.... el ciclo de S. Antonio Abad en Priverno, y los ejemplos posteriores de Pofi y de Cori» (op. cit., pp. 474-475), se puede confrontar ciertamente con las figuras monumentales de la Virgen y del Bautista colocados al lado del Cristo juez ya que presenta una serie de elementos formales análogos, cargados de expresionismo y de perseverantes tramas lineares.

${ }^{44}$ A. Bertini Calosso, «Le origini della pittura del Quattrocento intorno a Roma», Bollettino d' Arte 14 (1920), pp. 195196.
}

AEA, LXXVII, 2004, 305, pp. 35 a 57 


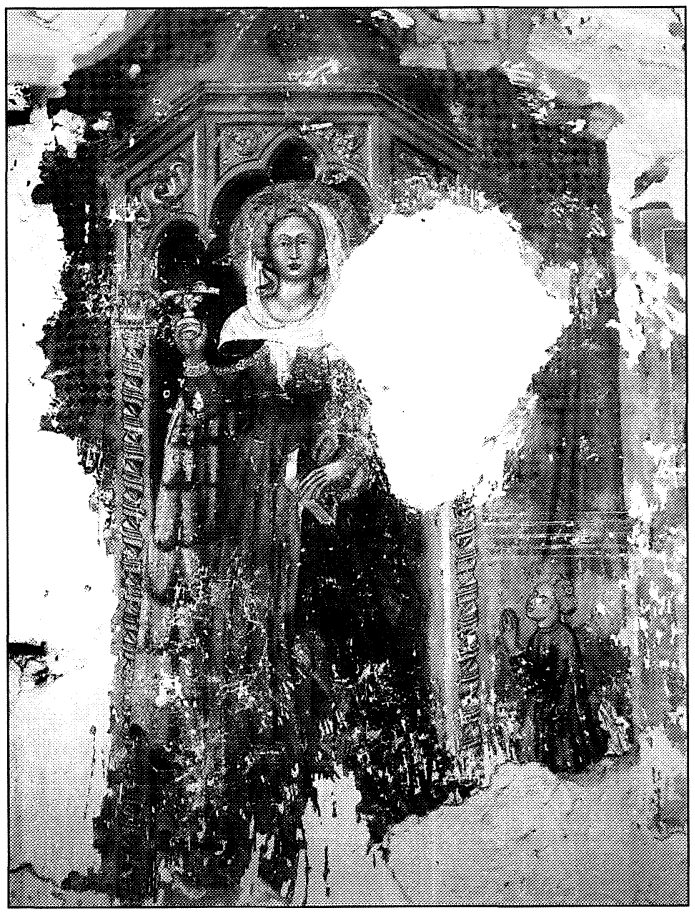

13

15

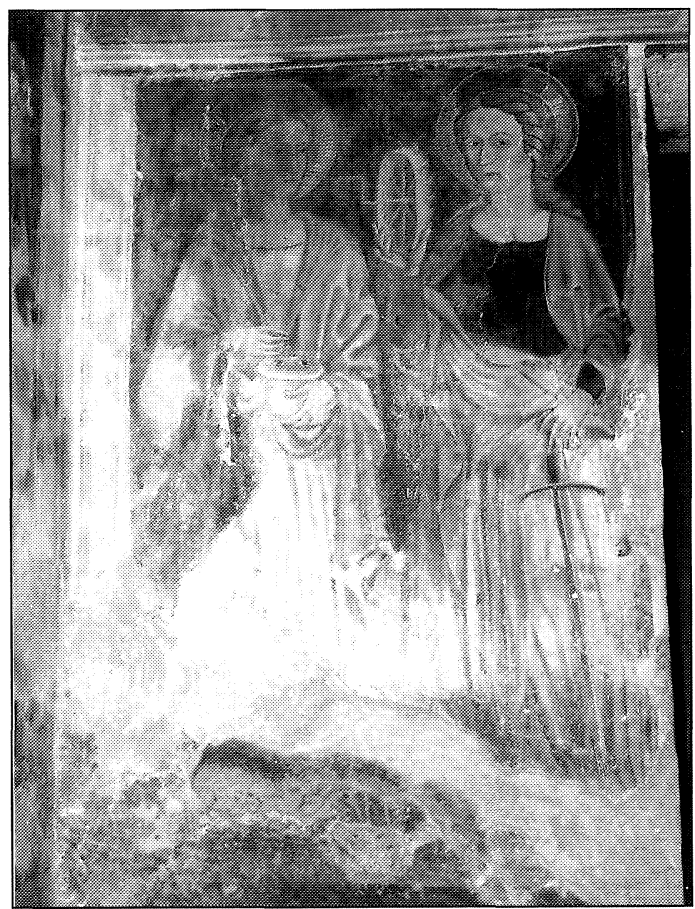

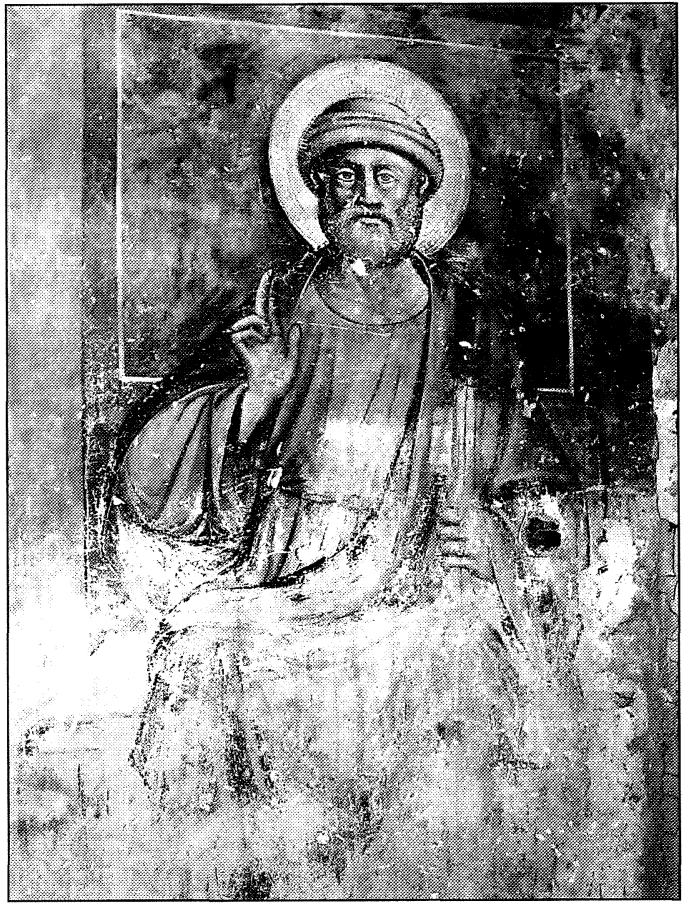

14

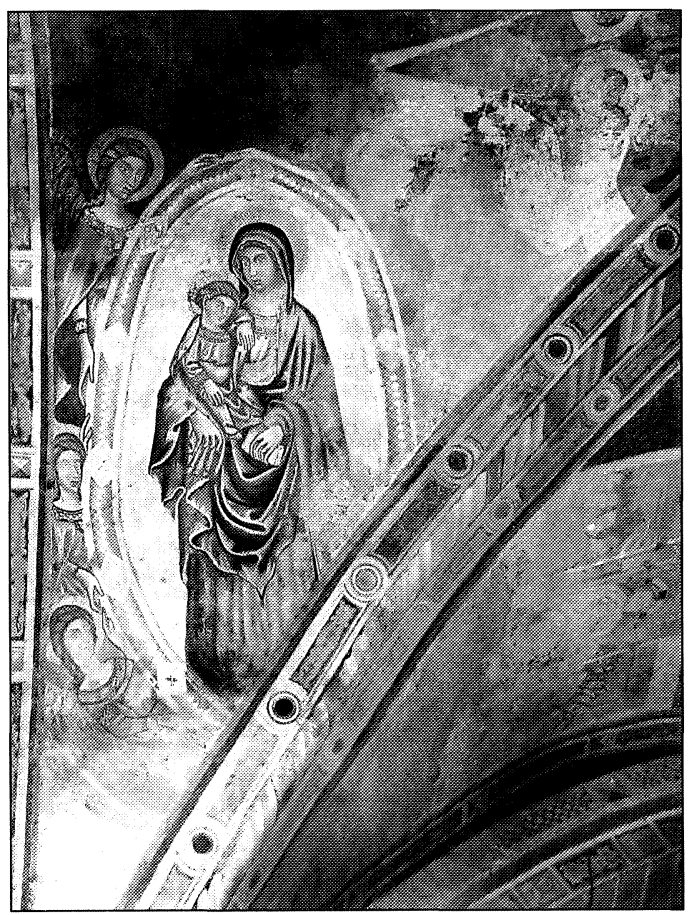

Fig. 13. Sermoneta, Iglesia de S. Miguel Arcángel, capilla inferior, Pietro Coleberti, Santa Lucía con el donante. Fig. 14. Fondi, Iglesia de San Pedro, primera capilla de la derecha, Discípulo de Pietro Coleberti, San Pedro.

Fig. 15. Cori, Oratorio de La Anunciación, pared interior de la fachada, Ayudante de Coleberti, Santa Lucía y Santa Catalina de Alejandría.

Fig. 16. Priverno, Iglesia de S. Antonio Abad, bóveda del presbiterio, Discípulo de Coleberti, Virgen con Niño y ángeles.

AEA, LXXVII, 2004, 305, pp. 35 a 57 


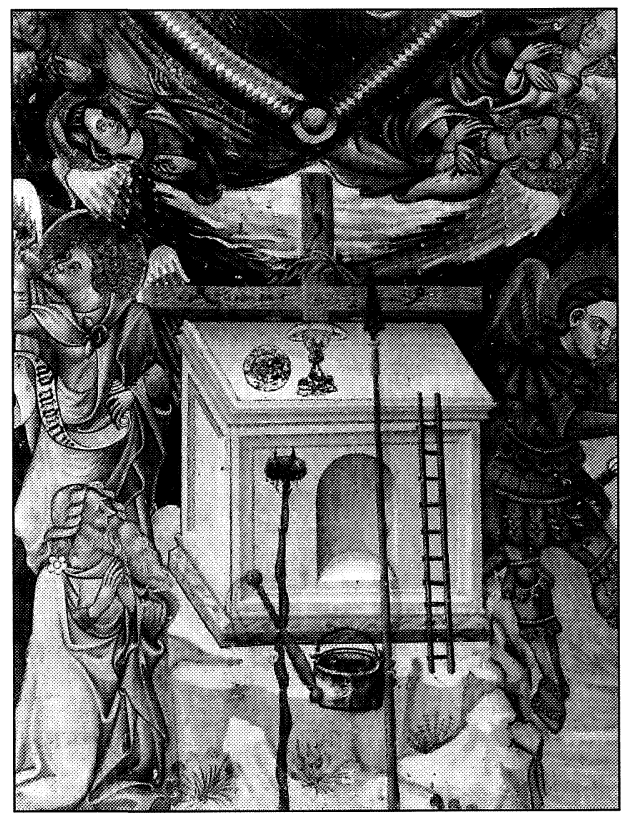

17

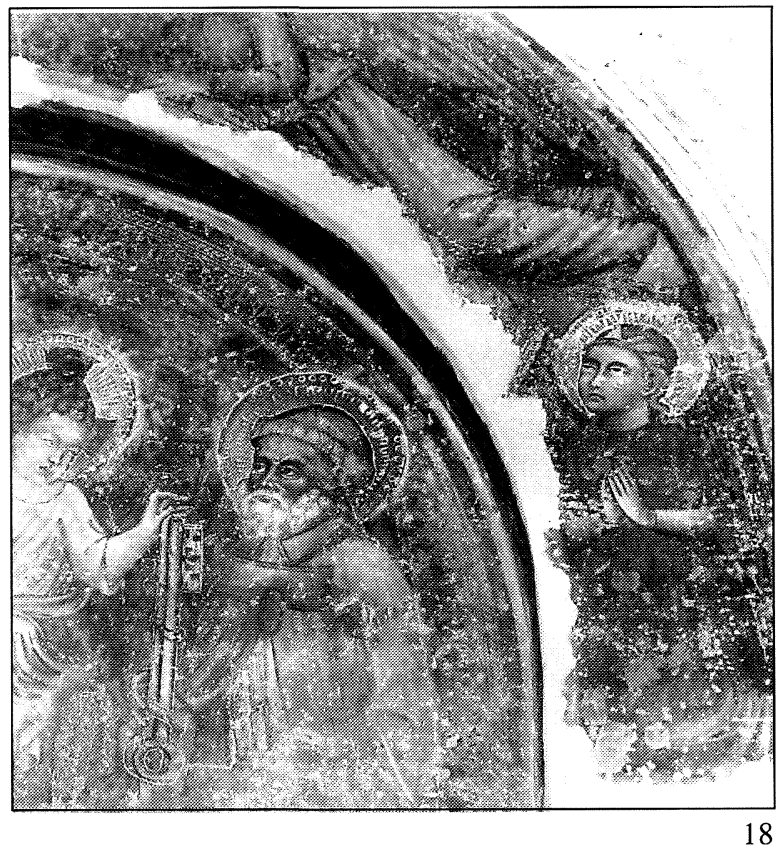

19

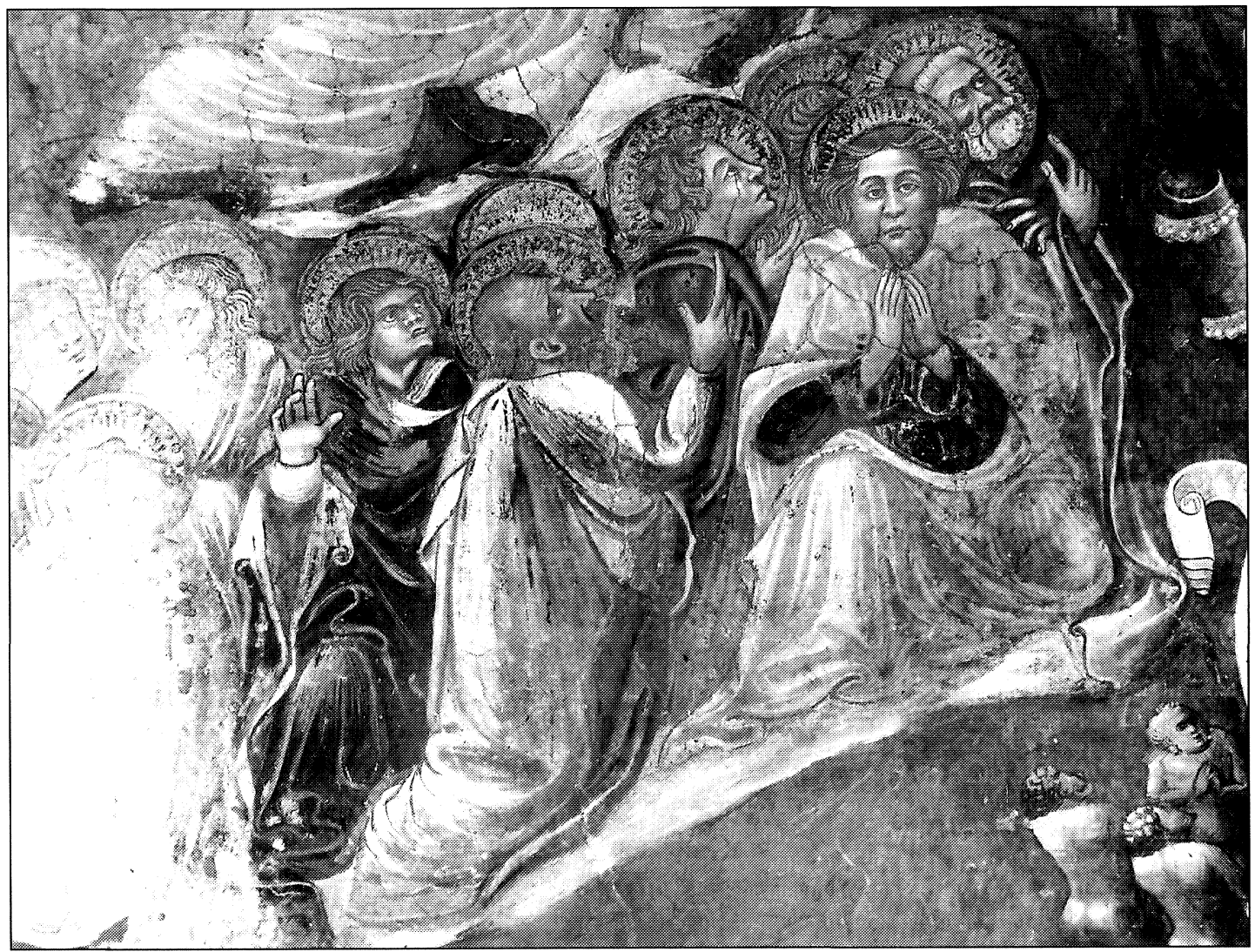

Fig. 17. Cori, Oratorio de La Anunciación, pared interior de la fachada, Pietro Coleberti, Juicio Universal (detalle).

Fig. 18. Sermoneta, Colegiata de La Asunción, portada central, Pietro Coleberti, Virgen con el Niño y con santos (detalle). Fig. 19. Cori, Oratorio de La Anunciación, pared interior de la fachada, Pietro Coleberti, Juicio Universal (detalle).

AEA, LXXVII, 2004, 305, pp. 35 a 57 


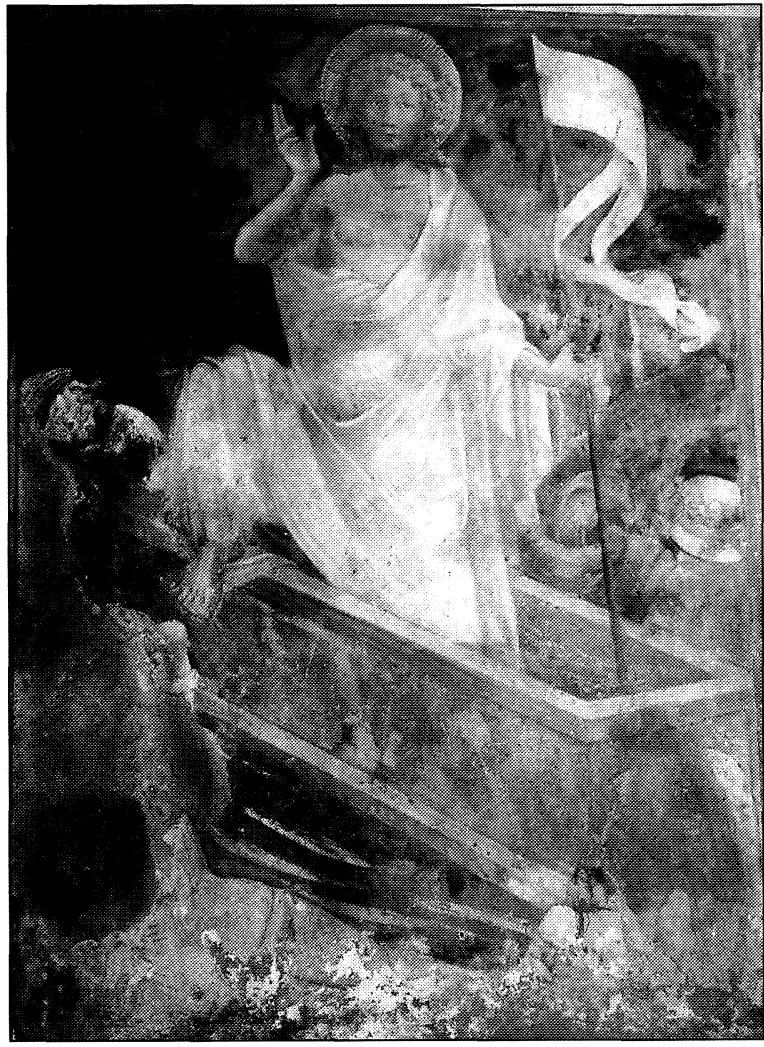

Fig. 20. Cori, Oratorio de La Anunciación, pared lateral, Tercer maestro, Resurrección. trazo inseguro. A estos episodios se añade el que aparece en la decoración de la bóveda del presbiterio de la iglesia de San Antonio Abad en Priverno (Fig. 16), la ciudad natal de Coleberti; Bertini Calosso ya había apreciado en este caso la intervención de un discípulo de este maestro y, efectivamente, tal decoración es obra de un alumno directo local cuyos elementos gráficos, de cierta tosquedad, le acercan al autor de los frescos de La Anunciación. En cambio, en Cori es posible reconocer el modo de hacer del propio Coleberti en el grupo de santos que se hallan a la izquierda del Juicio, sobre la escena de la Resurrección de los muertos, así como en la figura de Adán arrodillado bajo el altar que ostenta los símbolos de la Pasión (Fig. 17). A diferencia del resto de la representación de la escena del Juicio Final, el dibujo y las expresiones en estas figuras presentan algunos elementos dignos de consideración, así como ciertos refinamientos como, por ejemplo, el típico ceño realizado mediante las líneas convergentes de las cejas y la nariz, que se repite cons-

tantemente en las figuras del ciclo de Roccantica, los detalles de la barba realizados con pincelada minuciosa que vinculan el santo más cercano al Cristo juez (Fig. 19) a la figura de San Pedro del tímpano de la portada de Sermoneta (Fig. 18) o, por último, la realzada plasticidad de las figuras de perfil que remiten, probablemente, a una serie de ejercicios juveniles en el vasto taller de Subiaco junto al Maestro de la capilla Caldora.

De la experiencia formativa de Subiaco, Coleberti extrajo una fórmula personal que simplificaba el refinado y complejo repertorio del Maestro Caldora reuniendo en una síntesis sencilla y repetitiva la consistencia plástica y el linearismo expresivo. Las indicaciones cronológicas proporcionadas por los emblemas de los patrocinadores españoles localizarían la presencia de Coleberti en Cori hacia la segunda mitad de la segunda década del s. xv (al menos desde el 1426), es decir, en el período en que se atestigua su residencia en Sermoneta y, por tanto, algunos años antes del ejercicio de su actividad en el territorio sabino, fechada en 1430.

La zona central del registro inferior de las paredes longitudinales presenta dos series de apóstoles, de cuerpo entero, una Piedad, una Resurrección (Fig. 20) y una imagen del Cristo en el limbo que se conserva sólo parcialmente a causa de la apertura de una puerta (Fig. 21). Los apóstoles (Figs. 22-23) así como la reducida imagen de Cristo muestran una coherencia estilística y manifiestan la intervención de un notable maestro que concluyó la empresa decorativa de Cori. Hermanin propuso reconocer en estas figuras la producción de un maestro romano directamente vinculado a Masolino en calidad de ayudante en Castiglione Olona, una hipótesis defendida también por Venturi y por Bertini Calosso ${ }^{45}$. De hecho, la ausencia relati-

${ }^{45}$ A. Venturi, Storia dell' Arte Italiana, V, 1, p. 166; A. Bertini Calosso, art. cit., pp. 114 y 208.

$A E A$, LXXVII, 2004, 305, pp. 35 a 57 

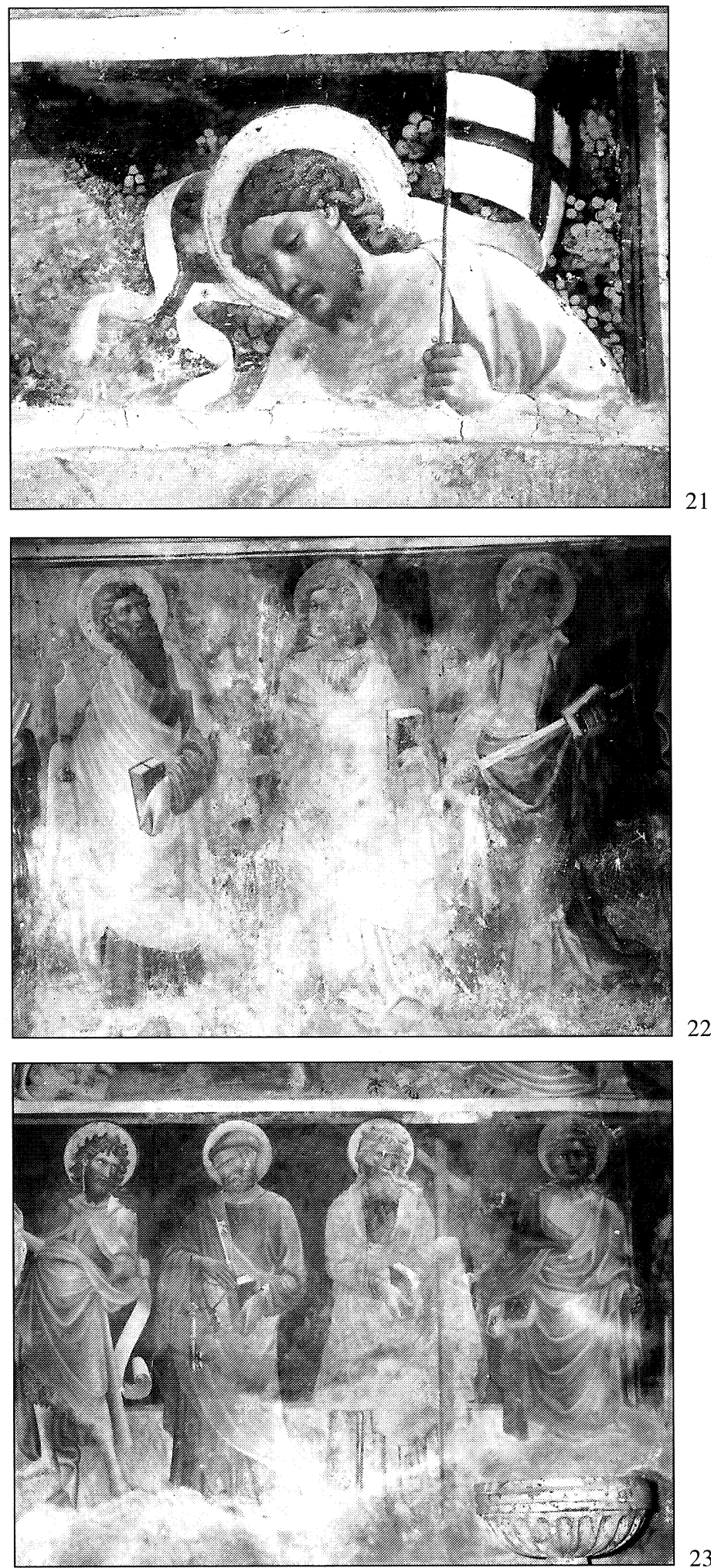

Fig. 21. Cori, Oratorio de La Anunciación, pared lateral, Tercer maestro, Cristo en el limbo. Fig. 22. Cori, Oratorio de La Anunciación, pared lateral, Tercer maestro, Apóstoles. Fig. 23. Cori, Oratorio de La Anunciación, pared lateral, Tercer maestro, Apóstoles. 
va de talentos en el panorama de la pintura romana de las primeras décadas del s. xv parece confirmar ulteriormente la situación de pobreza cultural que repercute en la Roma del cautiverio aviñonense al menos desde medio siglo atrás, es decir desde las perdidas decoraciones vaticanas de Matteo Giovannetti de Viterbo. En la tercera fase de la decoración de Cori se alcanzan cotas inigualables respecto de toda la producción lacial de mediados del s. xv, hallándose muy por encima del nivel de las decoraciones del oratorio de La Anunciación de Riofreddo o de las máximas expresiones pictóricas logradas por los artistas de Subiaco. Últimamente Toscano, oponiéndose a la lectura florentina, ha trasladado la atención hacia otra área cultural, alternativa e igualmente importante, como es la que representa Bartolomeo de Foligno y toda esa koiné que se extendía desde la costa de las Marcas, atravesaba el sur de Umbría y llegaba hasta la Roma de Nicolás $\mathrm{V}$ precisamente a mediados de siglo. La importancia de Umbría en cuanto filtro y puerta de acceso de las directrices culturales más importantes de Roma en la mitad del s. Xv se halla confirmada por la presencia en la Urbe de figuras como Bonfigli, que fue otro de los elementos de la difusión de un florentinismo mediado y refinado de la nueva vanguardia representada en Roma por el binomio Angelico-Benozzo Gozzoli. A este último le tocó la tarea de extraer las consecuencias que favorecieron los mayores logros de la pintura lacial de la mitad del s. xv, apartándose de las figuras ya consolidadas como Antonio de Viterbo para formar una serie de grupos de pintores locales que mantuvieron viva, desde Vicovaro en Farfa hasta la isla Bisentina, aquella síntesis de solemnidad en las formas y de compostura narrativa que logró fecundar, con una fuerza creativa intacta, las reflexiones juveniles de los mayores talentos de la región romana de la segunda mitad del s. xv, Antoniazzo Romano y Lorenzo de Viterbo ${ }^{46}$. Como Toscano ha notado correctamente ${ }^{47}$, la reconstrucción histórica del área cultural de Cori hacia mediados del s. xv se mueve en el terreno de las hipótesis a causa de la completa incertidumbre que rodea a las realizaciones de la contigua escuela de Velletri, de la que se conserva únicamente una obra firmada por Lello de Velletri y una serie de testimonios documentales sobre algunos artífices como Giovanni de Velletri y Luciano de Giovanni. La obra de Lello que subsiste en Perugia hace suponer la observancia que hacía esta escuela de los principios de Gentile, al menos en lo que se refiere a sus principios originarios. Aceptando la posibilidad del parentesco entre Giovanni de Velletri y Luciano, se puede decir que este fue el último exponente de aquella escuela, hipótesis que cuenta con el apoyo de ciertos documentos de Siena que atestiguan su actividad en 1441, en las pinturas al fresco del hospital de Santa María della Scala, que no se conservan, y en las que trabajó junto a Domenico de Bartolo en el mismo año en que comenzaba la actividad de Vecchietta en aquel taller. El hecho de que probablemente el maestro de Velletri y este último artista (tras la empresa for-

\footnotetext{
${ }^{46}$ La difusión de la cultura de Benozzo en la región lacial fue señalada brevemente por F. Zeri, «Una pala d'altare di Lorenzo da Viterbo», Bollettino d' Arte 38 (1953), pp. 38-44, esp. 44, recordando en una nota las dos pequeñas capillas franciscanas de la Isla Bisentina junto a Bolsena, las dos capillas decoradas de la iglesia convetual de S. Cosimato en Vicovaro y el llamado coro cuadrado junto al campanario de la iglesia de la abadía de Farfa. Si para estos tres ejemplos existe una coherencia estilística segura que remite a un pintor que procede probablemente de Viterbo, fiel seguidor de Benozzo y al que se le atribuye también la decoración de los cuatro templetes de la iglesia de Santa María della Febbre en Rocca di Botte (Abruzos), recordada por el proprio Zeri, para el resto de las indicaciones que este estudioso ofrece respecto de la tabla de la Virgen y cuatro santos de la Pinacoteca Comunale de Spoleto y de los famosos frescos del Palacio Ducal de Tagliacozzo, cabe señalar que pertenecen a un filón cultural diferente, tal y como recientemente ha confirmado B. Toscano, «Jacopo Vincioli», Prospettiva 33-36 (1984), pp. 62-75. Últimamente, el autor de estas líneas ha subrayado la importancia de la difusión de la cultura de Benozzo en la cultura pictórica lacial y romana durante el pontificado de Barbo: vid. S. Petrocchi, «La pittura a Roma all' epoca di Paolo II Barbo. Giuliano Amidei papae familiari», en Le due Rome del Quattrocento, Atti del convegno (Roma 1996), Roma 1997, pp. 225-235.

${ }^{47}$ Estos autores, mencionados por primera vez por A. Bertini Calosso, art. cit., pp. 204-205, han sido tomados de nuevo en consideración recientemente por B. Toscano en un ensayo que constituye el estudio más importante que se ha publicado sobre la cultura artística de la región pontina en el s. Xv: «Un problema di geografia artistica tra Roma e l' area di Ninfa», en L. Fiorani (ed.), Ninfa. Una città, un giardino, Atti del convegno, Roma 1990, p. 191.
}

AEA, LXXVII, 2004, 305, pp. 35 a 57 
mativa masolinesca de Castiglione Olona) se encontrasen allí, crea un hipotético y sugestivo contacto que obliga a considerar de nuevo la lectura originaria propuesta por Hermanin. De hecho, el maestro de Cori presenta una lectura de la cultura de Masolino extremadamente cercana a la de Vecchietta, aun cuando se pueda notar un acabado gráfico realizado de forma diferente, así como una actitud que deja traslucir un modo de hacer intensamente dependiente todavía del gusto del gótico tardío. Obviamente, dada la ausencia de obras, la eventual cohesión entre Luciano de Giovanni de Velletri y el maestro de Siena, así como sus relaciones con la herencia florentina no son demostrables; sólo se puede constatar que el maestro que trabajaba en Cori cerca ya de la quinta década del s. XV reflexionaba todavía, y sólo él —aparentemente- en la región lacial, sobre la herencia de la pintura florentina en Roma a través de sus máximos exponentes, Masolino y Massaccio, si bien restituyéndole los tonos y los modos de la Roma del gótico tardío de Gentile da Fabriano, autor del que quizá se pueda atestiguar su presencia en Foligno, según parece deducirse de un reciente descubrimiento, para trabajar en el palacio de los Trinci precisamente hacia el $1410^{48}$.

(Trad. Diana Segarra Crespo)

\footnotetext{
${ }^{48}$ La lectura todavía inedita de un manuscrito del s. xviII conservado en Foligno y que ha sido descubiero por una estudiosa local, Laura Lametti, parece aludir a una serie de pagos realizados a Gentile entre el 1411 y el 1412 y a un grupo de colaboradores, entre los que se halla un Jacopo da Venezia, llevaría a la desconcertante hipótesis de la presencia en Foligno incluso de la figura más anciana de los Bellini. Debo a las estimulantes conversaciones con Serena Romano la sugerencia de confrontar las obras lombardas y sienesas de Vecchietta con estas pinturas al fresco del Tercer maestro de Cori. Respecto de la proximidad o del posible conocimiento recíproco entre ambos artistas, cabe recordar la ausencia de noticias sobre el maestro sienés precisamente en torno al 1437-1439, tal y como señala Bertelli (C. Bertelli, Masolino. Gli affreschi del Battistero di Castiglione di Olona, Milán 1997, p. 12), , es decir entre su colaboración con Masolino en Lombardía y su retorno a Siena, una cronología que coincide sugestivamente con los mismos años en que se coloca, presumiblemente, la actividad del último pintor de Cori.
} 